\title{
Entry and Product Variety with Competing Supply Chains*
}

\author{
Matteo Bassi ${ }^{\dagger} \quad$ Marco Pagnozzi Palvatore Piccolo $^{\ddagger}$
}

March 2015

\begin{abstract}
We study a model where an endogenous number of competing manufacturers located around a circle contract with exclusive retailers who are privately informed about their costs. The number of brands in the market (determined by the manufacturers' zero profit condition) depends on the presence of asymmetric information and on the types of contracts between manufacturers and retailers. With two-part tariffs, wholesale prices fully reflect retailers' costs; with linear contracts, wholesale prices are constant and independent of retailers' costs. The number of brands is lower (resp. higher) with asymmetric information than with complete information when contracts are linear (resp. with two-part tariffs). Moreover, although the number of brands is always higher with linear contracts than with two-part tariffs, joint profits of manufacturers and retailers are higher with linear prices. We also discuss manufacturers' incentives to choose different contract forms and analyze the effects of endogenous entry on welfare.
\end{abstract}

JEL Classification: D43, D82, L13, L51.

Keywords: Product Variety, Entry, Competing Supply Chains, Vertical Contracting, Asymmetric Information.

\footnotetext{
*For extremely helpful comments, we would like to thank the Editor and the referees, as well as Alessandro Bonatti, Giacomo Calzolari, Yolande Hiriart, David Martimort, Jean-Charles Rochet, and Tommaso Valletti.

${ }^{\dagger} O F G E M$ and CSEF. Email: matteo.bassi@gmail.com

${ }^{\ddagger}$ Università di Napoli Federico II and CSEF. Email: pagnozzi@unina.it

${ }^{\S}$ Università Cattolica del Sacro Cuore (Milano) and CSEF. Email: salvapiccolo@gmail.com
} 


\section{Introduction}

Firms' entry and pricing decisions depend on the number and the characteristics of competing products supplied in a market. This paper analyzes the relationship between entry by vertically related firms, product differentiation and contracting under asymmetric information. ${ }^{1}$ In a simple model with an endogenous number of competing supply chains, each composed by a manufacturer and an exclusive retailer who is privately informed about his cost, we show how the equilibrium number of chains depends both on the type of wholesale contracts and on the presence of asymmetric information. ${ }^{2}$

Following the classic Salop (1979) model, we assume that supply chains that enter a market locate equidistantly on a circle where consumers are uniformly distributed. Consumers pay a transportation cost to reach a retailer and purchase its product. Each point on the circle may be interpreted as a possible variety of a product; a consumer's location represents its most preferred variety, while the supply chain's location represents the variety it produces. This model captures the idea that different consumers prefer different varieties of a product, and the number of competing supply chains that enter the market affects the degree of differentiation among their products. Since each supply chain produces a different variety, the entry of more supply chains implies that consumers are able to acquire a variety that is closer to their preferred one.

Our model can be seen as a simplified representation of various industries, such as traditional and business-format franchising (see, e.g., Lafontaine and Slade, 1997), where manufacturers choose to enter by selling differentiated products through exclusive retailers. ${ }^{3}$ As an example, consider the "fast fashion" market where large manufacturers (like Promod, Benetton, H\&M, etc.) sell to franchisee retailers with exclusive territories. In this market, manufacturers react to fast-changing fashion trends and consumers' volatile demand by delivering a multitude of upto-the-minute fashion products to exclusive retailers that manage to quickly reach the targeted local customers (Christopher and Towell, 2000). Other examples of industries where upstream suppliers distribute their products through exclusive retailers include: fast-food (e.g., McDonald's and Burger King), hotels (e.g., InterContinental, Wyndham, Marriott etc.), ice creams (e.g., Langnese-Iglo and Schöller in Germany), video rentals (Mortimer, 2008), beer distribution (Asker, 2005), and cars.

What is the impact of asymmetric information between manufacturers and retailers on the number of products offered in a market? How does the contracting environment (e.g., the manufacturers' selling conditions) affect market structure? What is the contractual structure

\footnotetext{
${ }^{1}$ There is a large empirical literature showing that asymmetric information affects strategic decisions in industries in which firms are vertically separated (see, e.g., Lafontaine and Slade, 1997, and Lafontaine and Shaw, 1999).

${ }^{2}$ Reisinger and Schnitzer (2012), discussed below, is the fist paper that analyzes the effects of alternative forms of vertical restraints with an endogenous market structure, but assumes complete information.

${ }^{3}$ Exclusive dealings are widespread in many industries and have been analyzed in a large theoretical literature — see, e.g., Bonanno and Vickers, (1988), Caillaud et al. (1995), Gal-Or (1991, 1999) and Jullien and Rey (2007).
} 
that maximizes social welfare?

To address these issues, we analyze manufacturers' entry decisions with two alternative contractual structures: one where they offer two-part tariffs (i.e., a fixed fee and a linear wholesale price); the other where they offer a linear wholesale price. Both these types of contracts are standard in the vertical contracting literature. Two-part-tariffs are usually seen as pro-competitive relative to linear prices because they avoid double marginalization and guarantee a higher social welfare - see, e.g., Motta (2004, Ch. 6). However, linear prices are much simpler and do not require the payment of up-front fees that could prevent capital constrained retailers from accepting contractual offers. Our analysis will suggest that, with an endogenous market structure, linear prices may arise because competing supply chains obtain higher profit if they jointly adopt this type of contracts rather than two-part tariffs. The empirical literature that tests whether retail prices are consistent with contracts that impose a uniform price or allow for quantity discounts shows that both forms of contracts are used in actual markets. ${ }^{4}$

We characterize market equilibria with two-part tariffs and linear prices under asymmetric information and compare them with the corresponding complete information benchmarks. To analyze how alternative wholesale contracts affect the market structure, we also compare equilibria across contractual types. Our results are the followings.

When manufacturers offer two-part tariffs, the unique equilibrium with asymmetric information entails a separating outcome: retailers fully reveal their costs to manufacturers and wholesale prices fully reflect this information. Moreover, the equilibrium number of products is larger with asymmetric information than with complete information - i.e., asymmetric information enhances entry. This is because, when retailers are privately informed about their cost, manufacturers increase wholesale prices above the complete information benchmark in order to reduce retailers' information rents. Hence, retail prices are higher too and, ceteris paribus, sales revenues increase relative to their complete information level. The positive strategic effect of asymmetric information always dominates the cost of information rents, thus inducing more manufacturers to enter the market. This suggests that, with two-part tariffs, better monitoring technologies (which reduce adverse selection between manufacturers and retailers) are likely to have a negative impact on product variety.

By contrast, when manufacturers offer linear contracts, in the unique equilibrium with asymmetric information manufacturers offer a constant wholesale price - a result that echoes Akerlof's lemon problem. Specifically, when wholesale contracts do not include a fixed component, manufactures cannot induce retailers to truthfully reveal their costs, because retailers would always claim to have the most efficient cost in order to obtain the lowest possible wholesale price. Hence, only pooling contracts are offered in equilibrium. But since wholesale prices do not depend on retailers' costs, efficient retailers obtain a lower demand with asymmetric information.

\footnotetext{
${ }^{4}$ Linear prices are used in mainstream department stores or grocery retailing (Iyer and Villas-Boas, 2003) and in the U.K. grocery industry for milk, bakery and fresh products (Inderst and Valletti, 2009). On the other hand, non-linear prices are consistent with U.S. data on yogurt consumption (Berto Villas-Boas, 2007) and French data on bottled water consumption (Bonnet and Dubois, 2010).
} 
As a result, fewer manufacturers enter the market and the number of products is lower than with complete information. This suggests that, in contrast to the case of two-part tariffs, with linear contracts better monitoring technologies are likely to have a positive impact on product variety.

Moreover, the equilibrium number of products is higher with linear contracts than with twopart tariffs, both with complete and with asymmetric information. This result hinges on the double marginalization effect of linear wholesale pricing: compared to two-part tariffs, linear prices induce manufacturers to increase wholesale prices to obtain a positive revenue. Ceteris paribus, this increases (average) retail prices and wholesale revenues, which makes entry in the market more profitable.

Hence, our analysis contributes to the empirical literature testing whether actual prices are consistent with linear contracts or two-part tariffs: empirical predictions of our model are that wholesale prices that do not depend on retailers' costs are only consistent with linear contracts and that, other things being equal, linear contracts should be associated with lower market concentration.

On the normative side, we also study the impact of asymmetric information on welfare when entry is endogenous. When contracts between manufacturers and retailers are based on two-part tariffs, a social planner would like manufacturers to be fully informed about downstream costs, because social welfare is higher with complete information. Surprisingly though, when contracts between manufacturers and retailers are linear, a social planner prefers retailers to have private information, even if this leads to wholesale prices that do not depend on marginal costs - i.e., social welfare is higher with asymmetric information. So transparency policies that eliminate asymmetric information may reduce welfare when firms use linear prices.

Finally, while social welfare is always higher with two-part tariffs than with linear prices (for a given information structure), the joint profits of manufacturers and retailers are higher with linear prices. This suggests that, if competing manufacturers could jointly commit to using a particular type of contracts with their retailers, they would choose linear prices rather than two-part tariffs. However, linear prices may be harder to sustain for manufacturers, since they have an individual incentive to choose a different contractual form when competitors use linear prices, but not when they use two-part tariffs.

By endogenizing entry in a model with competing supply chains under asymmetric information, our analysis contributes both to the vertical contracting literature and to the literature on product differentiation and product diversity. First, with the exception of Raith (2003), existing models of vertical contracting under asymmetric information usually assume an exogenous market structure - see, e.g., Blair and Lewis (1994), Gal-Or (1991, 1999), Kastl et al. (2011), and Martimort (1996). Second, very few models offer insights on the link between entry incentives and the selling conditions offered by manufacturers to retailers. Reisinger and Schnitzer (2012) consider non-exclusive vertical relationships with endogenous entry both in the upstream and in the downstream market, but assume perfect information. They show that total profits are 
determined by the competitive conditions in the downstream market, while competitive conditions in the upstream market mainly affect the distribution of profits. Reisinger and Schnitzer (2012) also analyze both two part-tariffs and linear contracts and, in line with our findings, show that welfare is larger with linear prices because they induce more downstream firms to enter, although two-part tariffs avoid double marginalization. ${ }^{5}$

Our paper is also related to the delegation literature that analyzes manufacturers' incentives to sell through independent retailers - see, e.g., McGuire and Staelin (1983), Coughlan (1985), Bonanno and Vickers (1988), and Cachon and Harker (2002). This literature shows that, when wholesale contracts are observable, vertical separation increases manufacturers' profits, because it allows them to soften downstream competition by charging higher wholesale prices. We obtain a similar result when we compare manufacturers' profits with and without asymmetric information when contracts are based on two-part tariffs, even though we assume that contracts are secret. ${ }^{6}$ This is a crucial difference because, with secret contracts and two-part tariffs, the delegation literature shows that manufacturers do not obtain higher profit by selling through retailers when there is no asymmetric information (Coughlan and Wernerfelt, 1989; Katz, 1991). In our model the wedge between wholesale prices and marginal costs is exclusively driven by the retailers' private information, which leads manufacturers to offer higher wholesale prices to reduce retailers' information rent.

Finally, although we consider a simple model where each manufacturer only deals with one retailer (as in, e.g., Bonanno and Vickers, 1988, and Vickers, 1985), our insights apply more generally to any industry in which upstream suppliers deal with multiple exclusive downstream outlets, if upstream suppliers eliminate intra-brand competition (between outlets of the same supplier) by granting exclusive territories (Rey and Stiglitz, 1995).

The rest of the paper is organized as follows. Section 2 presents the model. We characterize the equilibrium with two-part tariffs in Section 3 and with linear prices in Section 4. Section 5 compares two-part tariffs and linear pricing. Finally, in Section 6 we analyze welfare in the two contractual environments. Section 7 concludes. All proofs are in the Appendix.

\section{The Model}

Players and Environment. We consider a market described by the "circular city" model of Salop (1979). There is a unit mass of consumers uniformly distributed with density 1 around a circle of perimeter 1 . Goods are distributed by $N$ supply chains (firms) located equidistantly around the circle (see, e.g., Raith, 2003), and each composed by one upstream supplier (or manufacturer) $M_{i}$ and one exclusive downstream buyer (or retailer) $R_{i}$. There is a fixed entry cost $F>0$ that a manufacturer has to pay to enter the market and distribute its product, and

\footnotetext{
${ }^{5}$ For a similar model with Cournot competition in the upstream and downstream markets see Ghosh and Morita (2007).

${ }^{6}$ Arguably, secret contracts are more realistic because, even if contracts are observable, they can be secretly renegotiated.
} 
the number of firms $N$ in the market is determined by a zero profit condition for manufacturers, that reflects the assumption of free entry and exit (see, e.g., Raith, 2003). ${ }^{7}$

A manufacturer supplies a fundamental input to his retailer, that is used to produce a final good. Each consumer has a valuation $v$ for a single unit of the good, where for simplicity $v$ is large enough so that each consumer always buys one unit, regardless of the price. Consumers pay a linear transportation cost to reach firms (that can be interpreted as the loss of utility for purchasing a variety of the good that is different from the preferred). Specifically, a consumer located at $x \in\left[0, \frac{1}{N}\right]$ between firm $i$ and firm $j$ pays a transportation cost equal to $t x$ to buy from firm $i$ and to $t\left(\frac{1}{N}-x\right)$ to buy from firm $j$. Hence, letting $p_{i}$ be the retail price of firm $i$, the consumer is indifferent between the two firms if and only if

$$
p_{i}+t x=p_{j}+t\left(\frac{1}{N}-x\right) \Leftrightarrow x\left(p_{i}, p_{j}\right) \equiv \frac{p_{j}-p_{i}+\frac{t}{N}}{2 t}
$$

Letting $p_{i-1}$ and $p_{i+1}$ be the prices charged by the firms located to the left and to the right of firm $i$ respectively, the total demand of firm $i$ (in an interior solution) $)^{8}$ is

$$
D_{i}\left(p_{i}, p_{i-1}, p_{i+1}\right)=x\left(p_{i}, p_{i-1}\right)+x\left(p_{i}, p_{i+1}\right)=\frac{p_{i-1}+p_{i+1}-2 p_{i}}{2 t}+\frac{1}{N} .
$$

If all his rivals charge the same price $p$, firm $i$ 's demand is

$$
D_{i}\left(p_{i}, p\right)=\frac{p-p_{i}}{t}+\frac{1}{N}
$$

Uncertainty. Retailers are privately informed about their (constant) marginal costs of production. ${ }^{9} \quad R_{i}$ 's marginal cost is $\theta_{i}$, which is distributed uniformly on the compact support $\Theta \equiv[\mu-\sigma, \mu+\sigma]$, with mean $\mu>\sigma$, so that marginal costs are always positive, and variance $\sigma^{2} / 3>0$. We denote by $G(\cdot)$ and $g(\cdot)$ the corresponding distribution and density functions. We assume that $\sigma<\frac{1}{6} \sqrt{F t} \equiv \bar{\sigma}$. This assumption ensures that firms' production costs cannot be too asymmetric, so that the demand of each firm is always positive in a symmetric equilibrium and retailers do not have an incentive to undercut competitors "discontinuously" — i.e., by reducing their demand to zero — in any of the models that we analyze (see the Appendix). ${ }^{10}$ For simplicity, manufacturers' marginal costs of production are normalized to zero. ${ }^{11}$

\footnotetext{
${ }^{7}$ This can be interpreted as the result of a model in which a large number of manufacturers sequentially decide whether to enter the market (and then locate equidistantly once all firms willing to enter have done so).

${ }^{8}$ We are going to assume that all firms have positive demand (see below). This implies that each consumer buys from one of the two firms between which he is located, and that the demand of a firm only depends on the prices charged by its closest competitors.

${ }^{9}$ Our main results holds also when retailers are privately informed about demand (see Remark 2 below).

${ }^{10}$ As discussed in Vogel (2008), to avoid non-existence of equilibrium in the Salop model with heterogeneous firms, firms' marginal costs must be sufficiently similar. An alternative assumption that ensures equilibrium existence is that, because of attention limits, a consumer can only buy from one of its two nearest retailers.

${ }^{11}$ The assumption that only retailers are privately informed about their production costs is consistent with the adverse selection literature, that focuses on the effects of the information rents obtained by a privately informed agent who contracts with a principal with full bargaining power. Introducing private information on
} 
Asymmetric information between manufacturers and retailers may arise because, when contracting with manufacturers, retailers are privately informed about the costs of other inputs such as labor, energy, and rental costs, that are not directly related to the provision of the manufacturers' essential input and are provided by other independent suppliers. Alternatively, asymmetric information may arise because retailers are privately informed about their production efficiency.

Vertical Contracting. Contracts between manufacturers and retailers are secret and cannot be observed by competitors (e.g., because of the possibility of secret renegotiation). Following the vertical contracting literature, we consider the following two alternative types of contracts, ${ }^{12}$ and we use the Revelation Principle to characterize the equilibrium of the model — see, e.g., Myerson (1982) and Martimort (1996).

- Two-part tariffs: $M_{i}$ offers a contract $\left\{w_{i}\left(m_{i}\right), T_{i}\left(m_{i}\right)\right\}_{m_{i} \in \Theta}$ to $R_{i}$, which is a direct revelation mechanism that specifies a (linear) wholesale price $w_{i}\left(m_{i}\right)$ and a (fixed) franchise fee $T_{i}\left(m_{i}\right)$ both contingent on $R_{i}$ 's report $m_{i}$ about his cost $\theta_{i}$.

- Linear (wholesale) contracts: $M_{i}$ offers a contract $\left\{w_{i}\left(m_{i}\right)\right\}_{m_{i} \in \Theta}$ to $R_{i}$, which is a direct revelation mechanism that only specifies a (linear) wholesale price $w_{i}\left(m_{i}\right)$ contingent on $R_{i}$ 's report $m_{i}$ about his cost $\theta_{i}$.

The empirical literature shows that both types of contracts are used in practice. By comparing these contracts, we will provide new insights that relate characteristics of the industry structure (i.e., the number of firms in the market) with the type of wholesale contracts used by firms.

Timing. Given a contract type, either two-part tariffs or linear pricing, the timing of the game is as follows:

1. Manufacturers enter the market and locate equidistantly around the circle.

2. Retailers privately observe their costs.

3. Manufacturers simultaneously offer contracts to retailers, who choose whether to accept them.

4. If a retailer accepts the contract offered by his manufacturer, he makes a report about his cost. Otherwise, manufacturers and retailers obtain their reservation utility (normalized to zero for simplicity).

5. Retailers choose prices, the market clears and contracts are executed.

manufacturers' marginal costs would not affect any of our qualitative results (Maskin and Tirole, 1990).

${ }^{12}$ See Remark 1 for a discussion of RPM contracts. 
The assumption that manufacturers contract with retailers only after entering into the market reflects the idea that entry is a major decision that constrain firms in the long-term, while contracts are more easily changed in the short run. This simplifies the model by making locations and contracts independent.

For most of the analysis the contract type will be taken as given. Section 5 analyzes the contract type that maximizes the joint profits of manufacturers and retailers, and manufacturers' incentives to offer a particular type of contract.

Equilibrium Concept. The solution concept is Perfect Bayesian Equilibrium (PBE). We restrict to symmetric equilibria where all manufacturers offer the same contract.

Since contracts are private, we have to make an assumption on retailers' beliefs about their competitors' behavior. Following most of the literature on private contracts (e.g., Caillaud et al., 1995, and Martimort, 1996), we assume that agents have passive beliefs - i.e., that, regardless of the contract offered by his own manufacturer, a retailer always believes that rival manufacturers offer the equilibrium contract, and that each retailer expects that rival retailers truthfully report their types to manufacturers in a separating equilibrium (see Myerson, 1982, for a game-theoretic foundation of these beliefs). The assumption that retailers expect other manufacturers to offer the equilibrium contract captures the idea that, since manufacturers are independent and act simultaneously, a manufacturer cannot signal to his retailer information that he does not posses about the other manufacturers' contract: the no signal what you do not know requirement introduced by Fudenberg and Tirole (1991). ${ }^{13}$ The assumption that retailers expect other retailers to truthfully report their types is consistent with the fact that communication within vertical structures is private, and hence retailers do not observe their competitors' reports. ${ }^{14}$

\section{Two-Part Tariffs}

In this section we assume that manufacturers offer menus of two-part tariffs.

\subsection{Complete Information within Hierarchies}

As a benchmark, consider the case of complete information within firms - i.e., assume that $M_{i}$ knows $R_{i}$ 's cost $\theta_{i}$, but does not observe $R_{j}$ 's cost. Consider an equilibrium in which retailers choose the retail price $p_{T}^{*}\left(\theta_{i}\right){ }^{15}$

\footnotetext{
${ }^{13}$ See Pagnozzi and Piccolo (2012) for an analysis of the role of beliefs when contracts between manufacturers and retailers are private.

${ }^{14}$ Since each retailer expects other manufacturers to offer their equilibrium contract, which must be incentive compatible in a separating equilibrium, passive beliefs are the most natural restriction to impose at the revelation stage.

${ }^{15}$ Of course, equilibrium prices also depends on the number of firms $N$. Throughout the paper, to save notation we suppress this dependence unless it is necessary to underline it.
} 
For any wholesale price $w_{i}$ charged by $M_{i}, R_{i}$ chooses the retail price that solves

$$
\max _{p_{i} \geq 0} D_{i}\left(p_{i}, \bar{p}_{T}^{*}\right)\left(p_{i}-w_{i}-\theta_{i}\right)
$$

where $\bar{p}_{T}^{*}=\frac{1}{2 \sigma} \int_{\mu-\sigma}^{\mu+\sigma} p_{T}^{*}\left(\theta_{i}\right) d \theta_{i}$ denotes the average equilibrium price. The solution of this problem identifies $R_{i}$ 's retail price function ${ }^{16}$

$$
p_{i}^{*}\left(w_{i}, \theta_{i}\right)=\frac{\theta_{i}+w_{i}+\bar{p}_{T}^{*}+\frac{t}{N}}{2}
$$

which is increasing in $R_{i}$ 's total marginal cost of production $\left(\theta_{i}+w_{i}\right)$ and in the expected price $\bar{p}_{T}^{*}$ charged by his rivals.

Consider now manufacturers' choice of contracts. When $M_{i}$ observes $R_{i}$ 's marginal cost, he fully extracts $R_{i}$ 's surplus by charging the franchise fee

$$
T_{i}^{*}\left(w_{i}, \theta_{i}\right)=D_{i}\left(p_{i}^{*}\left(w_{i}, \theta_{i}\right), \bar{p}_{T}^{*}\right)\left(p_{i}^{*}\left(w_{i}, \theta_{i}\right)-w_{i}-\theta_{i}\right)
$$

Hence, $M_{i}$ 's maximization program is

$$
\max _{w_{i}} D_{i}\left(p_{i}^{*}\left(w_{i}, \theta_{i}\right), \bar{p}_{T}^{*}\right)\left(p_{i}^{*}\left(w_{i}, \theta_{i}\right)-\theta_{i}\right)
$$

Notice that, since contracts are secret, strategic effects are absent - i.e., the choice of $w_{i}$ does not affect the pricing decision of rival retailers.

Lemma 1. With two-part tariffs and complete information, in a symmetric equilibrium $M_{i}$ sets a wholesale price $w_{T}^{*}\left(\theta_{i}\right)=0 \forall \theta_{i}$, and $R_{i}$ sets a retail price

$$
p_{T}^{*}\left(\theta_{i}\right) \equiv p_{i}^{*}\left(0, \theta_{i}\right)=\frac{t}{N}+\frac{1}{2}\left(\mu+\theta_{i}\right) \quad \forall \theta_{i}
$$

With complete information, manufacturers act as if integrated with retailers and choose a wholesale price equal to marginal cost (which is normalized to zero). Since contracts are secret, a higher wholesale price would reduce $R_{i}$ 's ability to compete with his rivals by undercutting them, without creating any beneficial strategic effect. Hence, given the rivals' behavior, a positive wholesale price would only reduce the profit that $M_{i}$ can extract from $R_{i}{ }^{17}$

Using the equilibrium retail price (3.3), when a manufacturer enters the market, his expected profits are

$$
\frac{1}{2 \sigma} \int_{\mu-\sigma}^{\mu+\sigma} D_{i}\left(p_{T}^{*}\left(\theta_{i}\right), \bar{p}_{T}^{*}\right)\left(p_{T}^{*}\left(\theta_{i}\right)-\theta_{i}\right) d \theta_{i}=\frac{\sigma^{2}}{12 t}+\frac{t}{N^{2}}
$$

\footnotetext{
${ }^{16}$ Details of the derivation of all expressions are in the Appendix.

${ }^{17}$ As in O'Brien and Shaffer (1992), manufacturers would benefit from jointly committing to higher wholesale prices, but have an individual incentive to undercut rivals.
} 
Setting this equal to $F$ yields the equilibrium number of products

$$
N_{T}^{*}=\frac{2 \sqrt{3} t}{\sqrt{12 F t-\sigma^{2}}}
$$

The equilibrium number of products is decreasing in the entry cost. Moreover, it is increasing in $\sigma$ because (indirect) profit functions are convex in prices. Hence, more uncertainty (as reflected by a larger $\sigma$ ) increases profits and hence the number of products that are offered in the market. Finally, a higher $t$ increases the number of products because higher transportation costs make products more differentiated from consumers' perspective, which increases prices and thus entry incentives.

\subsection{Asymmetric Information}

Assume now that retailers are privately informed about their marginal cost. In this case, retailers have an incentive to report a higher marginal cost in order to pay a lower fixed fee, yet producing at a lower cost. Therefore, manufacturers have to provide an information rent to retailers in order to induce truthful information revelation.

Consider a separating equilibrium in which retailers choose the retail price $p_{T}^{e}\left(\theta_{i}\right)$. Given a wholesale price $w_{i}\left(m_{i}\right), R_{i}$ chooses $p_{i}$ to solve

$$
\max _{p_{i} \geq 0} D_{i}\left(p_{i}, \bar{p}_{T}^{e}\right)\left(p_{i}-w_{i}\left(m_{i}\right)-\theta_{i}\right)
$$

where $\bar{p}_{T}^{e}=\frac{1}{2 \sigma} \int_{\mu-\sigma}^{\mu+\sigma} p_{T}^{e}\left(\theta_{i}\right) d \theta_{i}$ denotes the average equilibrium price. The price that maximizes $R_{i}$ 's expected profits is

$$
p_{i}^{e}\left(w_{i}\left(m_{i}\right), \theta_{i}\right)=\frac{\theta_{i}+w_{i}\left(m_{i}\right)+\bar{p}_{T}^{e}+\frac{t}{N}}{2} .
$$

Following a standard convention in the screening literature, $R_{i}$ 's expected utility when his cost is $\theta_{i}$ and he reports $m_{i}$ is

$$
u_{i}\left(m_{i}, \theta_{i}\right) \equiv D_{i}\left(p_{i}^{e}\left(w_{i}\left(m_{i}\right), \theta_{i}\right), \bar{p}_{T}^{e}\right)\left(p_{i}^{e}\left(w_{i}\left(m_{i}\right), \theta_{i}\right)-w_{i}\left(m_{i}\right)-\theta_{i}\right)-T_{i}\left(m_{i}\right)
$$

For a contract to be incentive compatible, truthfully reporting $m_{i}=\theta_{i}$ must maximize $R_{i}$ 's utility - i.e., the following local first- and second-order incentive constraints must hold ${ }^{18}$

$$
\begin{gathered}
\left.\frac{\partial u_{i}\left(m_{i}, \theta_{i}\right)}{\partial m_{i}}\right|_{m_{i}=\theta_{i}}=0 \Leftrightarrow \dot{T}_{i}\left(\theta_{i}\right)=-D_{i}\left(p_{i}^{e}\left(w_{i}\left(\theta_{i}\right), \theta_{i}\right), \bar{p}_{T}^{e}\right) \dot{w}_{i}\left(\theta_{i}\right) \quad \forall \theta_{i} . \\
\left.\frac{\partial^{2} u_{i}\left(m_{i}, \theta_{i}\right)}{\partial m_{i}^{2}}\right|_{m_{i}=\theta_{i}} \leq 0 \quad \Leftrightarrow \quad \dot{w}_{i}\left(\theta_{i}\right) \geq 0 .
\end{gathered}
$$

\footnotetext{
${ }^{18}$ In the Appendix, we show that these conditions are also sufficient for global incentive compatibility - i.e., $u_{i}\left(\theta_{i}, \theta_{i}\right) \geq u_{i}\left(m_{i}, \theta_{i}\right) \forall\left(m_{i}, \theta_{i}\right) \in \Theta^{2}$.
} 
Moreover, letting $u_{i}\left(\theta_{i}\right) \equiv u_{i}\left(\theta_{i}, \theta_{i}\right)$ denote $R_{i}$ 's utility when he reports his true type (i.e., his information rent), the participation constraint is

$$
u_{i}\left(\theta_{i}\right) \geq 0, \quad \forall \theta_{i}
$$

Therefore, $M_{i}$ solves the following maximization program

$$
\max _{w_{i}(\cdot), T_{i}(\cdot)} \int_{\mu-\sigma}^{\mu+\sigma}\left[D_{i}\left(p_{i}^{e}\left(w_{i}\left(\theta_{i}\right), \theta_{i}\right), \bar{p}_{T}^{e}\right) w_{i}\left(\theta_{i}\right)+T_{i}\left(\theta_{i}\right)\right] d \theta_{i}
$$

subject to conditions (3.5), (3.6) and (3.7).

Following Laffont and Martimort (2000, Ch. 3), we first ignore the constraint $\dot{w}_{i}\left(\theta_{i}\right) \geq 0$, and then check that it is actually satisfied in the equilibrium that we characterize. In the Appendix, we show that $u_{i}\left(\theta_{i}\right)$ is decreasing and the participation constraint is binding when $\theta_{i}=\mu+\sigma$ - i.e., $u_{i}(\mu+\sigma)=0$. Hence, $R_{i}$ 's rent is

$$
u_{i}\left(\theta_{i}\right)=\int_{\theta_{i}}^{\mu+\sigma} D_{i}\left(p_{i}^{e}\left(w_{i}(x), x\right), \bar{p}_{T}^{e}\right) d x
$$

This rent is increasing in consumers' demand because a retailer obtains a higher utility by reporting a higher marginal costs when this allows him to sell a higher quantity on average - i.e., the information rent of a type is increasing in the quantity sold by less efficient types. Notice also that, since the demand for the good sold by $R_{i}$ is decreasing in $p_{i}$, this provides an incentive for a manufacturer to increase the wholesale price to limit the retailer's rent (since by equation (3.4) retail prices are increasing in wholesale prices).

By a standard change of variables, the fixed fee is

$$
T_{i}\left(\theta_{i}\right)=D_{i}\left(p_{i}^{e}\left(w_{i}\left(\theta_{i}\right), \theta_{i}\right), \bar{p}_{T}^{e}\right)\left(p_{i}^{e}\left(w_{i}\left(\theta_{i}\right), \theta_{i}\right)-w_{i}\left(\theta_{i}\right)-\theta_{i}\right)-u_{i}\left(\theta_{i}\right) .
$$

Substituting this into (3.8) and integrating by parts, $M_{i}$ 's (relaxed) maximization program is

$$
\max _{w_{i}(\cdot)} \int_{\mu-\sigma}^{\mu+\sigma} D_{i}\left(p_{i}^{e}\left(w_{i}\left(\theta_{i}\right), \theta_{i}\right), \bar{p}_{T}^{e}\right)\left[p_{i}^{e}\left(w_{i}\left(\theta_{i}\right), \theta_{i}\right)-\theta_{i}-\frac{G\left(\theta_{i}\right)}{g\left(\theta_{i}\right)}\right] d \theta_{i} .
$$

Lemma 2. With two-part tariffs and asymmetric information, in a symmetric equilibrium $M_{i}$ sets a wholesale price

$$
w_{T}^{e}\left(\theta_{i}\right)=\theta_{i}-\mu+\sigma>0 \quad \forall \theta_{i}
$$

and $R_{i}$ sets a retail price

$$
p_{T}^{e}\left(\theta_{i}\right) \equiv p_{i}^{e}\left(w_{T}^{e}\left(\theta_{i}\right), \theta_{i}\right)=\theta_{i}+\sigma+\frac{t}{N} \quad \forall \theta_{i} .
$$

Moreover, for a given number of firms, retail prices are higher with asymmetric information than 
with complete information - i.e., $p_{T}^{e}\left(\theta_{i}\right)>p_{T}^{*}\left(\theta_{i}\right)$.

In order to trade-off efficiency and rents, manufacturers increase wholesale prices above the complete information benchmark (i.e., a double marginalization effect, which is positive for manufacturers in our context, since they can extract surplus through the fixed fee), and this distortion is increasing in $\sigma$. As a result, retail prices are higher too. Notice that this double marginalization result is not due to contracts being public as in the delegation literature, but it arises as an equilibrium result due to asymmetric information between manufacturers and retailers, even if manufacturers offer secret contracts.

Using the equilibrium retail price (3.11) and letting $u^{e}\left(\theta_{i}\right)$ denote the equilibrium rent of the retailer, the expected profits of a manufacturer who enters the market are

$$
\frac{1}{2 \sigma} \int_{\mu-\sigma}^{\mu+\sigma}\left\{D_{i}\left(p_{T}^{e}\left(\theta_{i}\right), \bar{p}_{T}^{e}\right)\left(p_{T}^{e}\left(\theta_{i}\right)-\theta_{i}\right)-u^{e}\left(\theta_{i}\right)\right\} d \theta_{i}=\underbrace{\frac{1}{N}\left[\frac{t}{N}+\sigma\right]}_{\text {sale revenues }}-\underbrace{\sigma\left[\frac{1}{N}-\frac{\sigma}{3 t}\right]}_{\text {information rent }} .
$$

These profits can be decomposed in two terms: sale revenues and information rents. This suggests a trade-off: more uncertainty (as reflected by a larger $\sigma$ ) makes the retailers' mimicking opportunities more profitable, whereby making truthful information revelation more costly; but a larger $\sigma$ also increases prices, and hence profit margins.

Setting this profit equal to $F$ yields the equilibrium number of products

$$
N_{T}^{e}=\frac{\sqrt{3} t}{\sqrt{3 F t-\sigma^{2}}}
$$

As with complete information, the number of products with asymmetric information is decreasing in $F$, and is increasing in $t$ and $\sigma$. Hence, lower uncertainty (i.e., a low $\sigma$ ), as for instance implied by better monitoring technologies in the upstream market, leads to fewer firms entering and hence to a lower product variety.

We now compare the complete information benchmark with the asymmetric information case.

Proposition 1. With two-part tariffs: (i) more firms enter with asymmetric information than with complete information - i.e., $N_{T}^{e}>N_{T}^{*}$ — and (ii) average retail prices are higher with asymmetric information than with complete information - i.e., $\bar{p}_{T}^{e}\left(N_{T}^{e}\right)>\bar{p}_{T}^{*}\left(N_{T}^{*}\right)$.

With asymmetric information, manufacturers charge higher wholesale prices in order to reduce retailers' information rents. Hence, as shown in Lemma 2, for a given number of firms retail prices and sales revenues are higher with asymmetric information than with complete information. This strategic effect dominates the cost of information rents and induces more manufacturers to enter the market with asymmetric information, in an attempt to make positive profits. Our result echoes the literature on strategic delegation: by increasing retailer's costs 
through a higher wholesale price, manufacturers increase the profitability of the market, and thus induce more entry. However, in contrast to this literature, our result does not hinge on the observability of contracts, but on the presence of asymmetric information. Therefore, with twopart tariffs, bad monitoring technologies that create adverse selection between manufacturers and retailers increase entry and hence product variety.

Even when taking into account the number of firms that enter the market, average equilibrium retail prices are higher with asymmetric information. This suggests that the effect of higher wholesale prices with asymmetric information dominates the (indirect) effect of the presence of more firms, which tends to reduce retail price because of more competition.

Remark 1. When manufacturers control retail prices (RPM), the equilibrium of the game is equivalent to the one in our model (both with and without asymmetric information). Specifically, this equivalence result holds when each manufacturer makes the retailer residual claimant of the sale revenues - i.e., $M_{i}$ chooses a wholesale price equal to zero and imposes a retail price to $R_{i}$ - because there is a one-to-one relationship between retail and wholesale prices - see, e.g., Bassi et al. (2015). ${ }^{19}$ Hence, the (second-best) optimal price with two-part tariffs is also optimal when manufacturers directly choose retail prices, so that choosing retail prices is equivalent to choosing wholesale prices. The neutrality of RPM is due to the so called "dichotomy result" that is standard in models with pure adverse selection - see Kastl et al. (2011) for an example where this result does not hold when adverse selection is combined with moral hazard.

Remark 2. With linear demand and constant marginal costs, the main qualitative insights of our model hold even with asymmetric information about demand rather than costs. Specifically, if retailers are privately informed about demand (for instance, about the uncertain size of the circle) manufacturers still need to provide positive rents in order to induce truthful information revelation by retailers, and these rents are increasing in the quantity of final product sold by each retailer, so that wholesale prices are still upward distorted. ${ }^{20}$

\section{Linear (Wholesale) Prices}

The theoretical literature has often considered linear contracts in vertical relationships (e.g., Katz, 1986; Inderst and Valletti, 2009), because of their simplicity and realism. As previously discussed, there is also a growing empirical literature showing that, in many industries, manufacturers actually use linear contracts. Hence, to gain insights that have direct implications for real-life practices, in this section we assume that manufacturers offer linear prices.

\footnotetext{
${ }^{19}$ Formally, $M_{i}$ offers the contract $\left\{p_{i}\left(m_{i}\right), T_{i}\left(m_{i}\right)\right\}_{m_{i} \in \Theta}$, which specifies a retail price $p_{i}(\cdot)$ and a fixed fee $T_{i}(\cdot)$ as a function of $R_{i}$ 's report $m_{i}$.

${ }^{20}$ Suppose, for example, that retailers' costs are common knowledge while the total size of the circle, say $\alpha$, is random and unknown to both manufacturers and retailers. It can be shown that, in this case, all our qualitative conclusions hold if retailers receive private i.i.d. signals (say $s_{i}, i=1,2$ ) about $\alpha$ and the conditional distribution function $F\left(\alpha \mid s_{i}\right)$ is linear. For correlated signals or the case where retailers are informed about $\alpha$ see, e.g., Gal-Or (1999) and Martimort and Piccolo (2010).
} 


\subsection{Complete Information within Hierarchies}

First assume that each manufacturer knows his retailer's marginal cost. Consider an equilibrium in which retailers choose the retail price $p_{L}^{*}\left(\theta_{i}\right)$. Since retailers solve the same program (3.1) as with two-part tariffs, for any wholesale price $w_{i}, R_{i}$ 's chooses the retail price

$$
p_{i}^{*}\left(w_{i}, \theta_{i}\right)=\frac{\theta_{i}+w_{i}+\bar{p}_{L}^{*}+\frac{t}{N}}{2}
$$

where $\bar{p}_{L}^{*}=\frac{1}{2 \sigma} \int_{\mu-\sigma}^{\mu+\sigma} p_{L}^{*}\left(\theta_{i}\right) d \theta_{i}$ denotes the average equilibrium price.

Hence, $M_{i}$ 's maximization problem is

$$
\max _{w_{i}} D_{i}\left(p_{i}^{*}\left(w_{i}, \theta_{i}\right), \bar{p}_{L}^{*}\right) w_{i}
$$

The first-order condition of this problem equalizes the marginal wholesale revenue to the manufacturer's cost (which is normalized to zero) - i.e.,

$$
\frac{\partial D_{i}\left(p_{i}^{*}\left(w_{i}, \theta_{i}\right), \bar{p}_{L}^{*}\right)}{\partial p_{i}} \frac{\partial p_{i}^{*}\left(w_{i}, \theta_{i}\right)}{\partial w_{i}} w_{i}+D_{i}\left(p_{i}^{*}\left(w_{i}, \theta_{i}\right), \bar{p}_{L}^{*}\right)=0 .
$$

Lemma 3. With linear wholesale prices and complete information, in a symmetric equilibrium $M_{i}$ sets a wholesale price

$$
w_{L}^{*}\left(\theta_{i}\right)=\frac{2 t}{N}+\frac{1}{2}\left(\mu-\theta_{i}\right) \quad \forall \theta_{i}
$$

and $R_{i}$ sets a retail price

$$
p_{L}^{*}\left(\theta_{i}\right) \equiv p_{i}^{*}\left(w_{L}^{*}\left(\theta_{i}\right), \theta_{i}\right)=\frac{3 t}{N}+\frac{1}{4}\left(3 \mu+\theta_{i}\right) \quad \forall \theta_{i} .
$$

Since $M_{i}$ cannot extract $R_{i}$ 's surplus through the franchise fee, to obtain a positive profit he chooses a positive wholesale price (rather than equal to zero as with two-part tariffs). This, however, also induces a higher retail price - a standard double marginalization result. The wholesale price is decreasing in $\theta_{i}$ : manufacturers want more inefficient retailers to pay a lower wholesale price in order to obtain a higher demand (since the retail price is increasing in $\theta_{i}$ ). As expected, both wholesale and retail prices are increasing in $t$ and $\mu$, and decreasing in $N$.

Using (4.2) and (4.3), when a manufacturer enters the market, his expected profits are

$$
\frac{1}{2 \sigma} \int_{\mu-\sigma}^{\mu+\sigma}\left[D_{i}\left(p_{L}^{*}\left(\theta_{i}\right), \bar{p}_{L}^{*}\right)\right] w_{L}^{*}\left(\theta_{i}\right) d \theta_{i}=\frac{\sigma^{2}}{24 t}+\frac{2 t}{N^{2}} .
$$

Setting this equal to $F$ yields the equilibrium number of products

$$
N_{L}^{*}=\frac{4 \sqrt{3} t}{\sqrt{24 F t-\sigma^{2}}}
$$

As with two-part tariffs, the equilibrium number of products with linear pricing and complete 
information is increasing in $\sigma$ and in $t$.

\subsection{Asymmetric Information}

Assume now that retailers are privately informed about their marginal costs. Consider a separating equilibrium in which retailers choose the retail price $p_{L}^{e}\left(\theta_{i}\right)$. Given that $M_{i}$ offers to $R_{i}$ a menu of linear wholesale prices $w_{i}\left(m_{i}\right)$, since retailers solve the same program as with two-part tariffs, $R_{i}$ chooses the retail price

$$
p_{i}^{e}\left(w_{i}\left(m_{i}\right), \theta_{i}\right)=\frac{\theta_{i}+w_{i}\left(m_{i}\right)+\bar{p}_{L}^{e}+\frac{t}{N}}{2},
$$

where $\bar{p}_{L}^{e}=\frac{1}{2 \sigma} \int_{\mu-\sigma}^{\mu+\sigma} p_{L}^{e}\left(\theta_{i}\right) d \theta_{i}$ denotes average equilibrium price.

$R_{i}$ 's expected utility when his cost is $\theta_{i}$ and he reports $m_{i}$ is

$$
u_{i}\left(m_{i}, \theta_{i}\right) \equiv D_{i}\left(p_{i}^{e}\left(w_{i}\left(m_{i}\right), \theta_{i}\right), \bar{p}_{L}^{e}\right)\left(p_{i}^{e}\left(w_{i}\left(m_{i}\right), \theta_{i}\right)-\theta_{i}-w_{i}\left(m_{i}\right)\right) .
$$

For a contract to be incentive compatible, truthfully reporting $m_{i}=\theta_{i}$ must maximize $R_{i}$ 's utility - i.e., the following local first-order incentive constraint must hold: ${ }^{21}$

$$
\left.\frac{\partial u_{i}\left(m_{i}, \theta_{i}\right)}{\partial m_{i}}\right|_{m_{i}=\theta_{i}}=0 \quad \Leftrightarrow \quad-D_{i}\left(p_{i}^{e}\left(w_{i}\left(\theta_{i}\right), \theta_{i}\right), \bar{p}_{L}^{e}\right) \dot{w}_{i}\left(\theta_{i}\right)=0 .
$$

This constraint has a simple interpretation. Since with linear prices $M_{i}$ cannot use the fixed fee to screen $R_{i}$ 's types, an incentive compatible contract either specifies a wholesale price that equalizes (expected) demand to zero - i.e., $D_{i}\left(p_{i}^{e}\left(w_{i}\left(\theta_{i}\right), \theta_{i}\right), \bar{p}_{L}^{e}\right)=0$ - which however would lead $R_{i}$ to always choose the lowest wholesale price that is offered, or it entails a pooling allocation - i.e., such that $\dot{w}_{i}\left(\theta_{i}\right)=0$ for any $\theta_{i}$ - which implies that there is no information transmission between $M_{i}$ and $R_{i} .{ }^{22}$ Hence, in an incentive feasible contract the wholesale price does not depend on $\theta_{i}$ - i.e., the upstream contracting game has only pooling equilibria.

Therefore, $M_{i}$ chooses the same wholesale price regardless of $R_{i}$ 's cost. Letting this unique wholesale price be $w_{i}, M_{i}$ solves

$$
\max _{w_{i}} \int_{\mu-\sigma}^{\mu+\sigma} D_{i}\left(p_{i}^{e}\left(w_{i}, \theta_{i}\right), \bar{p}_{L}^{e}\right) w_{i} d \theta_{i}
$$

The first-order condition equalizes the expected marginal wholesale revenue to the marginal cost of the manufacturer

$$
\int_{\mu-\sigma}^{\mu+\sigma}\left[\frac{D_{i}\left(p_{i}^{e}\left(w_{i}, \theta_{i}\right), \bar{p}_{L}^{e}\right)}{\partial p_{i}} \frac{\partial p_{i}^{e}\left(w_{i}, \theta_{i}\right)}{\partial w_{i}} w_{i}+D_{i}\left(p_{i}^{e}\left(w_{i}, \theta_{i}\right), \bar{p}_{L}^{e}\right)\right] d \theta_{i}=0
$$

\footnotetext{
${ }^{21}$ See Martimort and Semenov (2006).

${ }^{22}$ Again, this result would still hold with uncertainty about demand instead of costs.
} 
Lemma 4. With linear wholesale prices and asymmetric information, in a symmetric equilibrium $M_{i}$ sets a wholesale price

$$
w_{L}^{e}=\frac{2 t}{N} \quad \forall \theta_{i}
$$

and $R_{i}$ sets a retail price

$$
p_{L}^{e}\left(\theta_{i}\right) \equiv p_{i}^{e}\left(w_{L}^{e}, \theta_{i}\right)=\frac{3 t}{N}+\frac{1}{2}\left(\mu+\theta_{i}\right) \quad \forall \theta_{i} .
$$

Moreover, retail and wholesale prices are higher with complete information than with asymmetric information, for a given number of products - i.e., $p_{L}^{*}\left(\theta_{i}\right)>p_{L}^{e}\left(\theta_{i}\right)$ and $w_{L}^{*}\left(\theta_{i}\right)>w_{L}^{e}$ - if and only if $\theta_{i}<\mu$.

Although asymmetric information leads to wholesale prices that are independent of retailers' marginal costs, equilibrium retail prices do depend on retailers' costs because a retailer chooses a retail price that equalizes his marginal cost to marginal revenue.

In contrast to the case of two-part tariffs, with linear prices the comparison between wholesale and retail prices with and without asymmetric information is ambiguous and depends on the retailer's cost. Recall that, with complete information, the wholesale price is decreasing in $\theta_{i}$. By contrast, with asymmetric information, retailers pay the same wholesale price regardless of their costs. This wholesale price is higher than the one with complete information when $\theta_{i}$ is higher than its expected value. In this case, since retailers choose retail prices according to the same rule both with and without asymmetric information, the retail price with asymmetric information is higher than with complete information.

Using (4.5) and (4.6), when a manufacturer enters the market, his expected profits are

$$
\frac{1}{2 \sigma} \int_{\mu-\sigma}^{\mu+\sigma} D_{i}\left(p_{L}^{e}\left(\theta_{i}\right), \bar{p}_{L}^{e}\right) w_{L}^{e} d \theta_{i}=\frac{2 t}{N^{2}}
$$

Setting this equal to $F$ yields the equilibrium number of products with linear wholesale prices and asymmetric information,

$$
N_{L}^{e}=\sqrt{\frac{2 t}{F}} .
$$

In this case, neither $M_{i}$ 's profit nor the equilibrium number of products depend on $\sigma$ because wholesale prices are unresponsive to marginal costs and the demand function is linear in retail prices, which are also linear functions of costs.

We now compare the complete information benchmark with the asymmetric information case.

Proposition 2. With linear wholesale prices: $(i)$ more firms enter with complete information — i.e., $N_{L}^{*}>N_{L}^{e}$ - and (ii) average retail prices are higher with asymmetric information i.e., $\bar{p}_{L}^{e}\left(N_{L}^{e}\right)>\bar{p}_{L}^{*}\left(N_{L}^{*}\right)$. 
When retailers are privately informed about their marginal costs, manufacturers cannot induce them to truthfully reveal their type and the unique equilibrium entails a constant wholesale price. Hence, in contrast to the case of complete information, wholesale profits only depend on the expected marginal cost and not on its variance (although indirect profit functions are still convex in wholesale prices). Moreover, since manufacturers cannot adjust the wholesale price to retailers' costs with asymmetric information, they sell a lower quantity on average. Therefore, entry is less profitable than under complete information (in contrast to the case of two-part tariffs). This also implies that, with linear contracts, better monitoring technologies have a positive impact on product variety.

In the Appendix, we show that the comparison between average retail prices with and without asymmetric information only depends on $N$. Hence, entry by a larger number of firms with complete information implies lower average retail prices.

\section{Linear Prices vs. Two-Part Tariffs}

In this section, we compare linear prices with two-part tariffs in terms of number of products, retail prices and supply chains' joint profits. We also discuss reasons why each of these contractual structures may be adopted by firms.

Proposition 3. The equilibrium number of products is higher with linear contracts than with two-part tariffs, both with complete and with incomplete information: $N_{L}^{*}>N_{T}^{*}$ and $N_{L}^{e}>N_{T}^{e}$.

The average retail price is higher with linear contracts than with two-part tariffs, both with complete and with incomplete information: $\bar{p}_{L}^{*}\left(N_{L}^{*}\right)>\bar{p}_{T}^{*}\left(N_{T}^{*}\right)$ and $\bar{p}_{L}^{e}\left(N_{L}^{e}\right)>\bar{p}_{T}^{e}\left(N_{T}^{e}\right)$.

This result hinges on the double marginalization effect that emerges with linear wholesale pricing. In contrast to two-part tariffs, with linear pricing manufacturers increase wholesale prices above their marginal costs, in order to obtain a positive wholesale revenue. Ceteris paribus, this leads to higher retail prices and wholesale revenues, which make upstream entry more profitable. Therefore, when the market structure is endogenous, the number of firms that enter with linear prices is unambiguously larger than with two-part tariffs.

Notice that, by Propositions 1, 2 and 3: $N_{L}^{*}>N_{L}^{e}>N_{T}^{e}>N_{T}^{*}$. Therefore, entry incentives are maximized with linear contracts and complete information, and minimized with two-part tariffs and complete information. This provides an empirical prediction on the different number of manufacturers entering a market, and hence on market concentration, depending on the types of contracts with retailers and the presence of asymmetric information.

What type of contracts should one expect manufacturers to offer when they take into account the contracts' effects on retail prices and the market structure? To address this issue, we analyze whether the joint profit of each supply chain is higher when both chains use linear prices or when both chains use two-part tariffs. ${ }^{23}$ By Proposition 3, linear prices result in higher retail prices

\footnotetext{
${ }^{23}$ Since manufacturers make zero profits in equilibrium, this comparison simply requires to verify whether the retailers' rents are higher with two-part tariffs or linear prices.
} 
and a higher number of products. The first effect tends to increase profits, while the second one tends to reduce them. The next proposition shows that the first effect always dominates.

Proposition 4. Both with complete and with incomplete information, the total profits of a supply chain are higher with linear contracts than with two-part tariffs.

Hence, if supply chains could coordinate and jointly commit to a contractual regime exante, they would choose linear prices rather than two-part tariffs. This provides a possible justification for the use of linear prices in practice, especially in industries in which institutions like syndicates, trade associations, etc., facilitate coordination among competing firms.

However, as shown in the next proposition, if all supply chains choose linear prices, a manufacturer has an individual incentive to deviate and offer two-part tariffs to his retailer (both with complete and with incomplete information). By contrast, if all competing supply chains choose two-part tariffs, a manufacturer also prefers to offer two-part tariffs to his retailer (both with complete and with incomplete information). In other words, the equilibria with two-part tariffs characterized in Section 3 are robust to deviations in the choice of the contractual form by manufacturers; while the equilibria with linear prices characterized in Section 4 are vulnerable to such deviations.

Proposition 5. Endogenous contractual form: Both with complete and with incomplete information, a manufacturer has no incentive to deviate from an equilibrium in which all manufacturers offer two-part tariffs by offering linear prices; while a manufacturer has an incentive to deviate from an equilibrium in which all manufacturers offer linear prices by offering a two-part tariff.

This result suggests that, although linear prices yield higher total profit to supply chains, they may be more difficult to implement than two-part tariffs, because a manufacturer has an incentive to offer a two-part tariff to his retailer in order to undercut rivals and obtain positive profits, when rival manufacturers offer linear prices. In other words, if manufacturers independently choose the wholesale contract with their retailers, there is a unique equilibrium in which all manufacturers offer two-part tariffs.

\section{Welfare}

In Sections 3 and 4, we showed that the contractual structure between manufacturers and retailers and the presence of asymmetric information affect both the number of firms that enter the market and the retail price that they charge to consumers. In this section, we analyze the effects on ex-ante social welfare.

Since each consumer always purchases one unit of the good, total demand and production are fixed and social welfare is the difference between consumers' value for the good and total costs. These costs are the sum of consumers', firms' and entry costs, and depend both on the number of 
firms and on the demand for each product, given the realized retail prices. Hence, what matters for welfare is: $(i)$ how far consumers travel to reach the firms from which they buy (depending on the distance between firms and on their relative prices), which affects transportation costs; (ii) how much each firm produces (depending on the firm's demand), which affects production costs; (iii) how many firms enter the market, which affects entry, production and transportation costs.

We first compare the actual number of products in the different contractual structures (derived in Sections 3 and 4) with the socially optimal number of products (derived in the Appen$\operatorname{dix})$.

Lemma 5. Both with two-part tariffs and with linear prices, the actual number of products is higher than the socially optimal number of products, with and without asymmetric information.

Therefore, in our model, there are always too many firms entering the market. This is consistent with the standard result of "excessive entry" in the Salop model and implies that social welfare is never maximized in any market equilibrium where entry is decided by manufacturers.

We then compare social welfare with different information structures.

Proposition 6. With two-part tariffs, social welfare is higher under complete information than under asymmetric information. With linear prices, social welfare is higher under asymmetric information than under complete information.

Hence, when contracts between manufacturers and retailers are based on two-part tariffs, a social planner prefers complete information, while he prefers asymmetric information when contracts are based on linear prices. To understand this result, notice that there are two differences between the regimes with and without asymmetric information: one depending on the sensitivity of prices to marginal costs and the other depending on the number of firms that enter the market.

First, in both contractual regimes, with asymmetric information retail prices are more sensitive to marginal costs and hence there are larger differences between firms' retail prices. When the number of firms in the market is the same with and without asymmetric information, this implies that: $(i)$ transportation costs are higher since it is more likely that a firm has a much lower price than competitors and hence there are more consumers willing to travel larger distances; and (ii) production costs are lower since it is more likely that a firm with lower costs attracts a larger share of demand (recall that the total quantity produced is fixed, so a low cost for one firm implies a shift of demand from high-cost firms to the low-cost firm).

Second, recall that the equilibrium number of firms is larger under asymmetric information with two-part tariffs but larger under complete information with linear prices: $N_{T}^{e}>N_{T}^{*}$ and $N_{L}^{*}>N_{L}^{e}$. A larger $N$ increases entry costs but tends to reduce total production costs since it increases the variability of realized costs (so that a larger share of demand is allocated to 
more efficient firms). The effect of a larger $N$ on transportation costs is ambiguous: a larger number of firms reduces the distance between them, which reduces transportation costs but it also makes it relatively more likely that a retailer has very low cost and hence a very low retail price, which induces consumers to travel further.

Therefore, with two-part tariffs, the effect of asymmetric information is to increase entry costs and reduce production costs; while in the Appendix we show that asymmetric information increases transportation costs. On balance, the effects of asymmetric information on entry and transportation costs are stronger than the effect on production costs and social welfare is higher under complete information.

By contrast, with linear prices, the effect of asymmetric information is to reduce entry costs and increase production costs; while in the Appendix we show that asymmetric information reduces transportation costs. On balance, the effects of asymmetric information on entry and production costs are stronger than the effect on transportation costs and social welfare is higher under asymmetric information.

Finally, we compare social welfare with different contractual structures.

Proposition 7. Welfare is always lower with linear pricing than with two-part tariffs.

Hence, welfare is higher with two-part tariffs regardless of the information structure, which is consistent with standard results that take as given the number of firms - see, e.g., Motta (2004). This depends on the following effects. With two-part tariffs, prices are more sensitive to marginal costs and hence are further away from each other (ceteris paribus), which increases transportation costs and reduces production costs. Moreover, fewer firms enter with two-part tariffs, which reduces entry costs but tends to increase production and transportation costs. In the appendix we show that overall costs are higher with linear prices.

\section{Conclusions}

Asymmetric information between manufacturers and retailers affects the variety of products offered and the number of firms active in a market. Following Salop (1979), we have considered competing supply chains that enter a market and locate on a circle where consumers are uniformly distributed. Our results contribute to the vertical contracting literature and to the literature on product differentiation and product diversity, which usually assume either an exogenous market structure or complete information.

When manufacturers offer two-part tariffs to their exclusive and privately informed retailers, retailers reveal their costs and wholesale prices fully reflect this information. In this case, the equilibrium number of products is higher with asymmetric information than with complete information. By contrast, when manufacturers offer linear contracts, manufacturers offer a constant wholesale price and the equilibrium number of products is lower with asymmetric information. 
As noted by Bonnet and Dubois (2010), a difficulty faced by the empirical literature on vertical contracts is that the type of contract adopted by firms is usually not observed, even in industries where wholesale prices are observed. Our model is relevant for this literature since it shows that, in the presence of asymmetric information, wholesale prices that do not depend on retailers' costs are consistent with the use of linear contracts but not with the use of two-part tariffs. Notice that this empirical prediction is independent of the magnitude of asymmetric information, which is difficult to measure in actual markets. Additional empirical predictions of our analysis are that, ceteris paribus, in industries where manufacturers use linear contracts: (i) product diversity is higher than in industries where manufacturers offer linear prices; (ii) market concentration does not depend on retailers' cost volatility, while in industries where manufacturers offer linear prices it does.

Finally, although welfare is higher with two-part tariffs, competing supply chains have an incentive to jointly commit to use linear contracts, since these contracts allow them to obtain higher rents than two-part tariffs. However, manufacturers also have an individual incentive to choose a different contractual form when competitors use linear prices, but not when they use two-part tariffs. 


\section{A. Appendix}

Proof of Lemma 1. Substituting (2.2), $R_{i}$ 's maximization problem is

$$
\max _{p_{i} \geq 0}\left(\bar{p}_{T}^{*}-p_{i}+\frac{t}{N}\right)\left(p_{i}-w_{i}-\theta_{i}\right)
$$

The first-order necessary and sufficient condition,

$$
w_{i}+\theta_{i}-2 p_{i}+\bar{p}_{T}^{*}+\frac{t}{N}=0
$$

yields (3.2).

Substituting (2.2) and (3.2), $M_{i}$ 's maximization problem is

$$
\max _{w_{i}}\left\{\left(\theta_{i}-\bar{p}_{T}^{*}-\frac{t}{N}\right)^{2}-w_{i}^{2}\right\}
$$

Since $M_{i}$ 's objective function is decreasing in $w_{i}$, it is optimal to set $w_{T}^{*}\left(\theta_{i}\right)=0 \quad \forall \theta_{i}$. Replacing the equilibrium wholesale price into (3.2) and taking expectations with respect to $\theta_{i}$ yields the average equilibrium price, $\bar{p}_{T}^{*}=\mu+\frac{t}{N}$. Finally, $p_{T}^{*}\left(\theta_{i}\right)$ is obtained by substituting $\bar{p}_{T}^{*}$ and $w_{T}^{*}\left(\theta_{i}\right)$ into (3.2).

Proof of Lemma 2. The first-order condition associated for $R_{i}$ 's maximization problem is

$$
\begin{gathered}
\frac{\partial D_{i}\left(p_{i}, \bar{p}_{T}^{e}\right)}{\partial p_{i}}\left(p_{i}-w_{i}\left(m_{i}\right)-\theta_{i}\right)+D_{i}\left(p_{i}, \bar{p}_{T}^{e}\right)=0, \\
\Leftrightarrow \quad w_{i}\left(m_{i}\right)+\theta_{i}+\bar{p}_{T}^{e}-2 p_{i}+\frac{T}{N}=0,
\end{gathered}
$$

where we have used $(2.2)$ and $\frac{\partial D_{i}\left(p_{i}, \bar{p}_{T}^{e}\right)}{\partial p_{i}}=\frac{1}{t}$. Rearranging yields (3.4).

Consider now $R_{i}$ 's information disclosure problem. To characterize the set of incentive feasible contracts let

$$
u_{i}\left(\theta_{i}, m_{i}\right) \equiv\left(p_{i}^{e}\left(w_{i}\left(m_{i}\right), \theta_{i}\right)-w_{i}\left(m_{i}\right)-\theta_{i}\right) D_{i}\left(p_{i}^{e}\left(w_{i}\left(m_{i}\right), \theta_{i}\right), \bar{p}_{T}^{e}\right)-T_{i}\left(m_{i}\right),
$$

with $u_{i}\left(\theta_{i}\right) \equiv \max _{\theta_{i} \in \Theta} u_{i}\left(\theta_{i}, m_{i}\right) . R_{i}$ truthfully reveals his cost only if the following first-order condition holds

$$
\left.\frac{\partial u_{i}\left(\theta_{i}, m_{i}\right)}{\partial m_{i}}\right|_{m_{i}=\theta_{i}}=0 \quad \Leftrightarrow \quad-\dot{w}_{i}\left(m_{i}\right) D_{i}\left(p_{i}^{e}\left(w_{i}\left(m_{i}\right), \theta_{i}\right), \bar{p}_{T}^{e}\right)-\left.\dot{T}_{i}\left(m_{i}\right)\right|_{m_{i}=\theta_{i}}=0 \quad \forall \theta_{i} \in \Theta .
$$

Differentiating $u_{i}(x)$ with respect to $x$ and using (A.3) yields

$$
\dot{u}_{i}(x)=-D_{i}\left(p_{i}^{e}\left(w_{i}(x), x\right), \bar{p}_{T}^{e}\right)
$$


and integrating $\dot{u}_{i}(x)$ between $\theta_{i}$ and $\mu+\sigma$ yields

$$
u_{i}\left(\theta_{i}\right)=u_{i}(\mu+\sigma)+\int_{\theta_{i}}^{\mu+\sigma} D_{i}\left(p_{i}^{e}\left(w_{i}(x), x\right), \bar{p}_{T}^{e}\right) d x .
$$

This is equation (3.9) when the participation constraint binds at $\mu+\sigma-$ i.e., when $u_{i}(\mu+\sigma)=$ 0 .

However, $m_{i}=\theta_{i}$ is an optimum for $R_{i}$ only if $u_{i}\left(\theta_{i}, m_{i}\right)$ is concave in $m_{i}$ at $m_{i}=\theta_{i}$. Using standard techniques (see, e.g., Laffont and Martimort, 2000), this requires

$$
\left.\frac{\partial^{2} u_{i}\left(\theta_{i}, m_{i}\right)}{\partial m_{i}^{2}}\right|_{m_{i}=\theta_{i}} \leq 0, \quad \forall \theta_{i} \in \Theta
$$

Since (A.3) must be satisfied for every $\theta_{i}$, differentiating with respect to $\theta_{i}$ yields

$$
\frac{\partial^{2} u_{i}\left(\theta_{i}, m_{i}\right)}{\partial m_{i}^{2}}+\left.\frac{\partial^{2} u_{i}\left(\theta_{i}, m_{i}\right)}{\partial m_{i} \partial \theta_{i}}\right|_{m_{i}=\theta_{i}}=0, \quad \forall \theta_{i} \in \Theta .
$$

Condition (A.4) together with (A.5) yield

$$
\begin{gathered}
\left.\frac{\partial^{2} u_{i}\left(\theta_{i}, m_{i}\right)}{\partial m_{i} \partial \theta_{i}}\right|_{m_{i}=\theta_{i}} \geq 0, \quad \forall \theta_{i} \in \Theta \\
\Rightarrow \quad-\left.\dot{w}_{i}\left(\theta_{i}\right) \frac{\partial p_{i}^{e}\left(w_{i}\left(m_{i}\right), \theta_{i}\right)}{\partial \theta_{i}} \frac{\partial D_{i}\left(p_{i}^{e}\left(w_{i}\left(m_{i}\right), \theta_{i}\right), \bar{p}_{T}^{e}\right)}{\partial p_{i}}\right|_{m_{i}=\theta_{i}} \geq 0, \quad \forall \theta_{i} \in \Theta .
\end{gathered}
$$

Since $\frac{\partial p_{i}^{e}\left(w_{i}\left(m_{i}\right), \theta_{i}\right)}{\partial \theta_{i}} \geq 0$ by (3.4) and $\frac{\partial D_{i}(.)}{\partial p_{i}}<0$ by (2.2) equation (A.6) implies (3.6).

Next, we determine the equilibrium wholesale price. The first-order necessary and sufficient condition associated to $M_{i}$ 's relaxed maximization program is

$$
\begin{gathered}
\frac{\partial D_{i}\left(p_{i}^{e}\left(w_{i}\left(\theta_{i}\right), \theta_{i}\right), \bar{p}_{T}^{e}\right)}{\partial p_{i}} \frac{\partial p_{i}^{e}\left(w_{i}\left(\theta_{i}\right), \theta_{i}\right)}{\partial w_{i}}\left[p_{i}^{e}\left(w_{i}\left(\theta_{i}\right), \theta_{i}\right)-\theta_{i}-\frac{G\left(\theta_{i}\right)}{g\left(\theta_{i}\right)}\right]+ \\
+D_{i}\left(p_{i}^{e}\left(w_{i}\left(\theta_{i}\right), \theta_{i}\right), \bar{p}_{T}^{e}\right) \frac{\partial p_{i}^{e}\left(w_{i}\left(\theta_{i}\right), \theta_{i}\right)}{\partial w_{i}}=0 .
\end{gathered}
$$

Notice that (A.1) implies

$$
D_{i}\left(p_{i}^{e}\left(w_{i}\left(\theta_{i}\right), \theta_{i}\right), \bar{p}_{T}^{e}\right)=-\frac{\partial D_{i}\left(p_{i}^{e}\left(w_{i}\left(\theta_{i}\right), \theta_{i}\right), \bar{p}_{T}^{e}\right)}{\partial p_{i}}\left(p_{i}^{e}\left(w_{i}\left(\theta_{i}\right), \theta_{i}\right)-w_{i}\left(\theta_{i}\right)-\theta_{i}\right) .
$$

Replacing this into (A.7) yields

$$
\frac{\partial D_{i}\left(p_{i}^{e}\left(w_{i}\left(\theta_{i}\right), \theta_{i}\right), \bar{p}_{T}^{e}\right)}{\partial p_{i}}\left[w_{i}\left(\theta_{i}\right)-\frac{G\left(\theta_{i}\right)}{g\left(\theta_{i}\right)}\right]=0,
$$

which yields the equilibrium wholesale price $w_{T}^{e}\left(\theta_{i}\right)$ in (3.10). Since $\dot{w}_{T}^{e}\left(\theta_{i}\right)>0$, the local secondorder incentive compatibility constraint (3.6) is satisfied. Inserting the equilibrium wholesale 
price into (3.4), and taking expectations with respect to $\theta_{i}$, yields $\bar{p}_{T}^{e}=\mu+\sigma+\frac{t}{N}$. The equilibrium price (3.11) is obtained by substituting $\bar{p}_{T}^{e}$ and (3.10) into (3.4).

To satisfy the global incentive constraint (A.2), the equilibrium contract must satisfy

$$
\begin{gathered}
u_{i}\left(\theta_{i}\right)-u_{i}\left(\theta_{i}, \theta_{i}^{\prime}\right) \geq 0 \quad \forall\left(\theta_{i}, \theta_{i}^{\prime}\right) \in \Theta^{2} \\
\Leftrightarrow \quad\left(p_{i}^{e}\left(w_{T}^{e}\left(\theta_{i}\right), \theta_{i}\right)-w_{T}^{e}\left(\theta_{i}\right)-\theta_{i}\right) D_{i}\left(p_{i}^{e}\left(w_{T}^{e}\left(\theta_{i}\right), \theta_{i}\right), \bar{p}_{T}^{e}\right)-T_{T}^{e}\left(\theta_{i}\right) \geq \\
\left(p_{i}^{e}\left(w_{T}^{e}\left(\theta_{i}^{\prime}\right), \theta_{i}\right)-w_{T}^{e}\left(\theta_{i}^{\prime}\right)-\theta_{i}\right) D_{i}\left(p_{i}^{e}\left(w_{T}^{e}\left(\theta_{i}^{\prime}\right), \theta_{i}\right), \bar{p}_{T}^{e}\right)-T_{T}^{e}\left(\theta_{i}^{\prime}\right) \\
\Leftrightarrow \quad \int_{\theta_{i}}^{\theta_{i}^{\prime}}\left\{\dot{w}_{T}^{e}(x) D_{i}\left(p_{i}^{e}\left(w_{T}^{e}(x), \theta_{i}\right), \bar{p}_{T}^{e}\right)+\dot{T}_{T}^{e}(x)\right\} d x \geq 0 .
\end{gathered}
$$

where $T_{T}^{e}(x)$ is the equilibrium fixed fee. Substituting $\dot{T}_{T}^{e}(x)=-\dot{w}_{T}^{e}(x) D_{i}\left(p_{i}^{e}\left(w_{T}^{e}(x), x\right), \bar{p}_{T}^{e}\right)$,

$$
\begin{aligned}
\int_{\theta_{i}}^{\theta_{i}^{\prime}}\left\{\dot{w}_{T}^{e}(x) D_{i}\left(p_{i}^{e}\left(w_{T}^{e}(x), \theta_{i}\right), \bar{p}_{T}^{e}\right)-\dot{w}_{T}^{e}(x) D_{i}\left(p_{i}^{e}\left(w_{T}^{e}(x), x\right), \bar{p}_{T}^{e}\right)\right\} d x & = \\
- & \int_{\theta_{i}}^{\theta_{i}^{\prime}}\left\{\dot{w}_{T}^{e}(x) \int_{\theta_{i}}^{x} \frac{\partial D_{i}\left(p_{i}^{e}\left(w_{T}^{e}(x), y\right), \bar{p}_{T}^{e}\right)}{\partial p_{i}} \frac{\partial p_{i}^{e}\left(w_{T}^{e}(x), y\right)}{\partial y} d y\right\} d x \geq 0 .
\end{aligned}
$$

Suppose, without loss of generality, that $\theta_{i}^{\prime}>\theta_{i}$ (so that $x>\theta_{i}$ ). Condition (3.6) - i.e., $\dot{w}_{T}^{e}(x)>0$ - and the fact that $\frac{\partial p_{i}^{e}(.)}{\partial y}>0 \frac{\partial D_{i}(.)}{\partial p_{i}}<0$ guarantee that the global incentive constraint holds.

If the number of products is the same both with complete and with asymmetric information, the equilibrium retail price is higher with asymmetric information since

$$
p_{T}^{e}\left(\theta_{i}\right)>p_{T}^{*}\left(\theta_{i}\right) \quad \Leftrightarrow \quad \theta_{i}>\mu-2 \sigma .
$$

This concludes the proof.

Positive Demand and No Discontinuous Deviation with Two-Part Tariffs. To ensure that, in the equilibrium characterized in Lemma 2, all retailers' demand is (strictly) positive regardless of their costs, assume that $R_{i}$ has the highest possible cost, $\mu+\sigma$, whereas his closest competitors, $R_{i-1}$ and $R_{i+1}$, have the lowest possible cost, $\mu-\sigma$. In this case, by (2.1), $R_{i}$ 's equilibrium demand is

$$
\begin{aligned}
D_{i}\left(p_{T}^{e}(\mu+\sigma), p_{T}^{e}(\mu-\sigma), p_{T}^{e}(\mu-\sigma)\right) & =\frac{p_{T}^{e}(\mu-\sigma)-p_{T}^{e}(\mu+\sigma)}{t}+\frac{1}{N_{T}^{e}} \\
& =\frac{\sqrt{3 F t-\sigma^{2}}-2 \sqrt{3} \sigma}{t},
\end{aligned}
$$

where we have used (3.11) and the equilibrium number of firms $N_{T}^{e}$. This is strictly positive when $\sigma<\sigma^{*} \equiv \sqrt{\frac{3 F t}{13}}$. Hence, in equilibrium, $R_{i}$ 's total demand is always positive regardless of his rivals' prices. 
Furthermore, under this assumption, $R_{i}$ 's expected equilibrium rent is positive, since

$$
\frac{1}{N_{T}^{e}}>\frac{\sigma}{3 t} \Leftrightarrow \sqrt{9 F t-3 \sigma^{2}}>\sigma
$$

and this inequality is always satisfied when $\sigma<\sigma^{*}$.

We now characterize a sufficient condition under which retailers have no incentive to deviate and undercut "discontinuously" their closer competitors - i.e., to choose a retail price such that a competitor's demand is reduced to zero - when retailers are privately informed about their costs and manufacturers offer the equilibrium two-part tariff characterized in Lemma 2. In order to do so, let us consider the scenario in which reducing competitors' demand to zero is easier and more profitable: $R_{i}$ has the lowest possible marginal cost - i.e., $\mu-\sigma-$ and its four closest competitors have the highest possible marginal cost - i.e., $\mu+\sigma$ - and choose the equilibrium retail price $p_{T}^{e}(\mu+\sigma)=\mu+2 \sigma+\frac{t}{N_{T}^{e}}$. If $R_{i}$ has no incentive to undercut discontinuously his competitors in this hypothetical scenario, then he also has no incentive to undercut discontinuously more efficient rivals.

Suppose that $R_{i}$ chooses the retail price that reduces to zero the demand of his two closest competitors - i.e.,

$$
p_{i}=\mu+2 \sigma
$$

At this retail price, the consumers located at a distance of $\frac{3}{2 N_{T}^{e}}$ to the left and to the right of $R_{i}$ (i.e., those located half-way between the two closest competitors to the left of $R_{i}$, and those located half-way between the two closest competitors to the right of $R_{i}$ ) are indifferent between buying from $R_{i}$ and buying from their closest retailers. Hence, recalling that $w_{T}^{e}(\mu-\sigma)=0$, $R_{i}$ 's total demand is equal to $\frac{3}{N_{T}^{e}}$ and his gross profit is

$$
\frac{3}{N_{T}^{e}}(\mu+2 \sigma-(\mu-\sigma))=\frac{9 \sigma}{N_{T}^{e}} .
$$

By contrast, by choosing the equilibrium retail price $p_{T}^{e}(\mu-\sigma), R_{i}$ obtains a gross profit equal to

$$
\left(\frac{p_{T}^{e}(\mu+\sigma)-p_{T}^{e}(\mu-\sigma)}{t}+\frac{1}{N_{T}^{e}}\right)\left(p_{T}^{e}(\mu-\sigma)-(\mu-\sigma)\right)=\left(\frac{2 \sigma}{t}+\frac{1}{N_{T}^{e}}\right) \frac{t}{N_{T}^{e}} .
$$

A sufficient condition that ensures that (A.9) is larger than (A.8) is

$$
\sigma \leq \bar{\sigma} \equiv \frac{\sqrt{F t}}{6}
$$

It can be shown that this condition also guarantees that retailers have no incentive to undercut "discontinuously" with complete information.

Finally, notice that $\bar{\sigma}<\sigma^{*}$.

Proof of Proposition 1. The equilibrium number of firms is higher with asymmetric information since

$$
N_{T}^{e}>N_{T}^{*} \Leftrightarrow \sqrt{12 F t-\sigma^{2}}>\sqrt{12 F t-4 \sigma^{2}} .
$$


Average retail prices with complete information are

$$
\bar{p}_{T}^{*}\left(N_{T}^{*}\right)=\mu+\frac{t}{N_{T}^{*}}=\mu+\sqrt{F t-\frac{\sigma^{2}}{12}},
$$

while average retail prices with asymmetric information are

$$
\bar{p}_{T}^{e}\left(N_{T}^{e}\right)=\mu+\sigma+\frac{t}{N_{T}^{e}}=\mu+\sigma+\sqrt{F t-\frac{\sigma^{2}}{3}} .
$$

It is straightforward to show that $\bar{p}_{T}^{e}\left(N_{T}^{e}\right)>\bar{p}_{T}^{*}\left(N_{T}^{*}\right)$.

Proof of Lemma 3. Substituting (2.2) and (4.1), $M_{i}$ 's maximization problem is

$$
\max _{w_{i}}\left(\bar{p}_{L}^{*}-\theta_{i}+w_{i}+\frac{t}{N}\right) w_{i}
$$

The necessary and sufficient first-order condition is

$$
\bar{p}_{L}^{*}-\theta_{i}-2 w_{i}+\frac{t}{N}=0 \quad \Leftrightarrow \quad w_{i}\left(\theta_{i}\right)=\frac{1}{2}\left(\bar{p}_{L}^{*}-\theta_{i}+\frac{t}{N}\right) .
$$

Taking expectations with respect to $\theta_{i}$ in (4.1), the average equilibrium price as a function of the expected wholesale price $\bar{w}_{L}^{*}$ is

$$
\bar{p}_{L}^{*}=\mu+\bar{w}_{L}^{*}+\frac{t}{N}
$$

Replacing this into $w_{i}\left(\theta_{i}\right)$ and taking expectations with respect to $\theta_{i}$ yields $\bar{w}_{L}^{*}=\frac{2 t}{N}$. Hence, the average equilibrium price is $\bar{p}_{L}^{*}=\mu+\frac{3 t}{N}$. Replacing it into $w_{i}\left(\theta_{i}\right)$ yields the equilibrium wholesale price (4.2). Finally, inserting (4.2) and $\bar{p}_{L}^{*}$ into (4.1) yields the equilibrium retail price (4.3).

Proof of Lemma 4. Substituting (2.2) and (4.4), $M_{i}$ 's maximization problem is

$$
\max _{w_{i}} \int_{\mu-\sigma}^{\mu+\sigma}\left(\bar{p}_{L}^{e}-\theta_{i}-w_{i}+\frac{t}{N}\right) w_{i} d \theta_{i} .
$$

The necessary and sufficient first-order condition is

$$
\bar{p}_{L}^{e}-\mu-2 w_{i}+\frac{t}{N}=0 \quad \Leftrightarrow \quad w_{i}=\frac{1}{2}\left(\bar{p}_{L}^{e}-\mu+\frac{t}{N}\right) .
$$

Taking expectations with respect to $\theta_{i}$ in (4.4), the average equilibrium price as a function of the expected wholesale price $\bar{w}_{L}^{e}$ is

$$
\bar{p}_{L}^{e}=\mu+\bar{w}_{L}^{e}+\frac{t}{N}
$$


Hence, (A.10) becomes

$$
w_{i}=\frac{1}{2}\left(\bar{w}_{L}^{e}+\frac{2 t}{N}\right)
$$

Setting $w_{i}=\bar{w}_{L}^{e}$ yields the equilibrium wholesale price (4.5). Moreover, $\bar{p}_{L}^{e}=\frac{3 t}{N}+\mu$. Finally, inserting (4.5) and $\bar{p}_{L}^{e}$ into (4.4) yields (4.6).

If the number of products $N$ is the same both with complete and with asymmetric information, the comparisons between $p_{L}^{*}\left(\theta_{i}\right)$ and $p_{L}^{e}\left(\theta_{i}\right)$ and between $w_{L}^{*}\left(\theta_{i}\right)$ and $w_{L}^{e}$ are straightforward.

No Discontinuous Deviation with Linear Prices. We now characterize a sufficient condition under which retailers have no incentive to deviate and undercut "discontinuously" their closer competitors, when retailers are privately informed about their costs and manufacturers offer the equilibrium linear prices characterized in Lemma 4. Following the same logic as with two-part tariffs, let us consider the scenario in which $R_{i}$ has the lowest possible marginal cost - i.e., $\mu-\sigma$ - and its four closest competitors have the highest possible marginal cost - i.e., $\mu+\sigma-$ and choose the equilibrium retail price $p_{L}^{e}(\mu+\sigma)=\mu+\frac{\sigma}{2}+\frac{3 t}{N_{T}^{e}}$.

Suppose that $R_{i}$ chooses the retail price that reduces to zero the demand of his two closest competitors - i.e.,

$$
p_{i}=\frac{2 t}{N_{L}^{e}}+\frac{1}{2}(2 \mu+\sigma) .
$$

At this retail price, the consumers located at a distance of $\frac{3}{2 N_{T}^{e}}$ to the left and to the right of $R_{i}$ are indifferent between buying from $R_{i}$ and buying from their closest retailers. Hence, recalling that $w_{L}^{e}=\frac{2 t}{N_{L}^{e}}, R_{i}$ 's total demand is equal to $\frac{3}{N_{T}^{e}}$ and his gross profit is

$$
\frac{3}{N_{T}^{e}}\left(\frac{2 t}{N_{L}^{e}}+\frac{1}{2}(2 \mu+\sigma)-(\mu-\sigma)-w_{L}^{e}\right)=\frac{9 \sigma}{2 N_{T}^{e}} .
$$

By contrast, by choosing the equilibrium retail price $p_{L}^{e}(\mu-\sigma), R_{i}$ obtains a gross profit equal to

$$
\left(\frac{p_{L}^{e}(\mu+\sigma)-p_{L}^{e}(\mu-\sigma)}{t}+\frac{1}{N_{L}^{e}}\right)\left(p_{L}^{e}(\mu-\sigma)-(\mu-\sigma)-w_{L}^{e}\right)=\left(\frac{\sigma}{t}+\frac{1}{N_{L}^{e}}\right) \frac{2 t+N_{L}^{e} \sigma}{2 N_{L}^{e}} .
$$

A sufficient condition that ensures that (A.12) is larger than (A.11) is

$$
\sigma \leq 3.9 \sqrt{F t},
$$

which is always satisfied for $\sigma \leq \bar{\sigma}$. It can be shown that this condition also guarantees that retailers have no incentive to undercut "discontinuously" with complete information.

Proof of Proposition 2. The equilibrium number of firms is higher with complete information since

$$
N_{L}^{*}>N_{L}^{e} \Leftrightarrow \sqrt{24 F t}>\sqrt{24 F t-\sigma^{2}} .
$$

Comparing average equilibrium retail prices with complete and asymmetric information from Lemmas 3 and $4, \bar{p}_{L}^{e}\left(N_{L}^{e}\right)>\bar{p}_{L}^{*}\left(N_{L}^{*}\right)$ since $N_{L}^{*}>N_{L}^{e}$. 
Proof of Proposition 3. With complete information,

$$
N_{L}^{*}>N_{T}^{*} \Leftrightarrow \sqrt{48 F t-4 \sigma^{2}}>\sqrt{24 F t-\sigma^{2}} .
$$

With asymmetric information,

$$
N_{L}^{e}>N_{T}^{e} \Leftrightarrow \sqrt{6 F t-2 \sigma^{2}}>\sqrt{3 F t} .
$$

Both inequalities are satisfied for $\sigma<\bar{\sigma}$.

Comparing the average retail prices with asymmetric information (computed in Lemma 2 and 4 ),

$$
\bar{p}_{L}^{e}\left(N_{L}^{e}\right)>\bar{p}_{T}^{e}\left(N_{T}^{e}\right) \Leftrightarrow 8 \sigma^{2}+21 F t-18 \sigma \sqrt{2 F t}>0 .
$$

The inequality is satisfied because the function on the left-hand-side is decreasing in $\sigma$ and strictly positive when $\sigma=\bar{\sigma}$. Finally, it is straightforward to show that $\bar{p}_{L}^{*}\left(N_{L}^{*}\right)>\bar{p}_{T}^{*}\left(N_{T}^{*}\right)$.

Proof of Proposition 4. With two-part tariffs, retailers' expected rent is

$$
u_{T}^{e}=\sigma\left[\frac{1}{N_{T}^{e}}-\frac{\sigma}{3 t}\right]=\frac{\sigma \sqrt{3 F t-\sigma^{2}}}{\sqrt{3} t}-\frac{\sigma^{2}}{3 t} .
$$

With linear prices, it can be shown that retailers' expected rent is

$$
u_{L}^{e}=\frac{t}{N_{L}^{e 2}}+\frac{\sigma^{2}}{12 t}=\frac{F}{2}+\frac{\sigma^{2}}{12 t} .
$$

Hence,

$$
u_{T}^{e}-u_{L}^{e}=\frac{\sigma}{t}\left[\frac{\sqrt{3 F t-\sigma^{2}}}{\sqrt{3}}-\frac{5 \sigma}{12}\right]-\frac{F}{2} .
$$

For $\sigma \in[0, \bar{\sigma}]$ this expression is strictly concave in $\sigma$. Moreover,

$$
u_{T}^{e}-\left.u_{L}^{e}\right|_{\sigma=0}=-\frac{F}{2}<0,
$$

and

$$
\lim _{\sigma \rightarrow \bar{\sigma}^{-}}\left[u_{T}^{e}-u_{L}^{e}\right]=-\frac{149 F}{523}<0
$$

Finally, since

$$
\lim _{\sigma \rightarrow \bar{\sigma}^{-}} \frac{\partial\left[u_{T}^{e}-u_{L}^{e}\right]}{\partial \sigma}=2.5 \sqrt{\frac{F}{t}}>0
$$

$u_{T}^{e}<u_{L}^{e}$ for $\sigma \in[0, \bar{\sigma}]$.

Proof of Proposition 5. We show that, under asymmetric information, if the type of contract between manufacturers and retailers is endogenous, there is a unique symmetric equilibrium in which manufacturers offer two-part tariffs (which is the equilibrium characterized in Lemma 2).

First, consider an equilibrium in which all manufacturers choose linear contracts and $N_{L}^{e}$ manufacturers enter into the market - i.e., the equilibrium characterized in Lemma 3. Suppose 
that one manufacturer, say $M_{i}$, deviates by offering a two-part tariff to his retailer. Then, it can be shown that $M_{i}$ offers a wholesale price

$$
w_{i}\left(\theta_{i}\right)=\frac{G\left(\theta_{i}\right)}{g\left(\theta_{i}\right)}
$$

and $R_{i}$ charges a retail price

$$
p_{i}\left(\theta_{i}\right)=\frac{\theta_{i}+\mu+\frac{G\left(\theta_{i}\right)}{g\left(\theta_{i}\right)}+\frac{4 t}{N_{L}^{e}}}{2} .
$$

Hence, $M_{i}$ 's expected gross profit from deviation is

$$
\frac{1}{2 \sigma} \int_{\mu-\sigma}^{\mu+\sigma} D_{i}\left(p_{i}\left(\theta_{i}\right), \bar{p}_{L}^{e}\right)\left[p_{i}\left(\theta_{i}\right)-\theta_{i}-\frac{G\left(\theta_{i}\right)}{g\left(\theta_{i}\right)}\right] d \theta_{i}=2 F+\frac{7}{12 t} \sigma^{2}-\sigma \sqrt{\frac{2 F}{t}} .
$$

This expression is higher than the equilibrium gross expected profit, which is equal to $F$, if and only if

$$
F>\sigma \sqrt{\frac{2 F}{t}}-\frac{7}{12 t} \sigma^{2}
$$

Since this inequality is always satisfied, the equilibrium in which all manufacturers choose linear contracts is not robust to deviations in the contract type.

Second, consider an equilibrium in which all manufacturers choose two-part tariffs and $N_{T}^{e}$ manufacturers enter into the market - i.e., the equilibrium characterized in Lemma 2. Suppose that one manufacturer, say $M_{i}$, deviates by offering a linear contract to his retailer. Then, it can be shown that, in order to maximize his expected (deviation) profit, $M_{i}$ offers a wholesale price

$$
w_{i}=\frac{\sigma}{2}+\sqrt{\frac{3 F t-\sigma^{2}}{3}}
$$

and $R_{i}$ charges a retail price

$$
p_{i}\left(\theta_{i}, w_{i}\right)=\frac{\theta_{i}+\mu+\frac{3 \sigma}{2}+2 \sqrt{\frac{3 F t-\sigma^{2}}{3}}+\frac{t}{N_{T}^{e}}}{2} .
$$

Hence, $M_{i}$ 's expected gross profit from deviation is

$$
\frac{1}{2 \sigma} \int_{\mu-\sigma}^{\mu+\sigma} D_{i}\left(p_{i}\left(\theta_{i}, w_{i}\right), \bar{p}_{T}^{e}\right) w_{i} d \theta_{i}=\frac{1}{72 t}\left(3 \sigma+2 \sqrt{3} \sqrt{3 F t-\sigma^{2}}\right)^{2} .
$$

This expression is lower than the equilibrium gross expected profit, which is equal to $F$, if and only if

$$
\sigma \sqrt{\frac{3 F t-\sigma^{2}}{3}}-\frac{\sigma^{2}}{12}<F t
$$

Since this inequality is always satisfied for $\sigma \leq \bar{\sigma}$, the equilibrium in which all manufacturers choose two-part tariffs is robust to deviations in the contract type.

Finally, it is clear that, with complete information and endogenous contracts, in the unique 
symmetric equilibrium manufacturers offer two-part tariffs (since the equilibrium characterized in Lemma 1 in which all manufacturers choose two-part tariffs is robust to deviations in the contract type; while the equilibrium characterized in Lemma 3 in which all manufacturers choose linear prices is not robust to deviations in the contract type).

Welfare Analysis. To highlight that actual demand depends on production costs through the realized retail prices, we define the (equilibrium) demand for firm $i$ as $D_{i}\left(\theta_{i}, \theta_{i-1}, \theta_{i+1}\right)$, where $\theta_{i-1}$ and $\theta_{i+1}$ are the marginal costs of the firms located to the left and to the right of firm $i$, respectively.

Let

$$
x\left(\theta_{i}, \theta_{i+1}\right) \equiv \frac{p_{i+1}\left(\theta_{i+1}\right)-p_{i}\left(\theta_{i}\right)+\frac{t}{N}}{2 t} .
$$

The transportation costs of firm $i$ 's consumers are the sum of the transportation costs of the consumers that are located to the left of firm $i$ and buy from firm $i-$ i.e., $\int_{0}^{x\left(\theta_{i}, \theta_{i-1}\right)} z d z-$ and the transportation costs of the consumers that are located to the right of firm $i$ and buy from firm $i$ - i.e., $\int_{0}^{x\left(\theta_{i}, \theta_{i+1}\right)} z d z$.

Consumers' total expected transportation costs are the sum of the transportation costs paid by consumers of all firms - i.e.,

$$
T C=\frac{t}{4 \sigma^{2}} \sum_{i=1}^{N}\left[\int_{\mu-\sigma}^{\mu+\sigma} \int_{\mu-\sigma}^{\mu+\sigma} \int_{0}^{x\left(\theta_{i}, \theta_{i+1}\right)} z d z d \theta_{i} d \theta_{i+1}+\int_{\mu-\sigma}^{\mu+\sigma} \int_{\mu-\sigma}^{\mu+\sigma} \int_{0}^{x\left(\theta_{i}, \theta_{i-1}\right)} z d z d \theta_{i} d \theta_{i-1}\right] .
$$

Firm $i$ 's production costs are $\theta_{i} D_{i}\left(\theta_{i}, \theta_{i-1}, \theta_{i+1}\right)$. Hence, firms' total expected production costs are

$$
P C=\frac{1}{8 \sigma^{3}} \sum_{i=1}^{N} \int_{\mu-\sigma}^{\mu+\sigma} \int_{\mu-\sigma}^{\mu+\sigma} \int_{\mu-\sigma}^{\mu+\sigma} \theta_{i} D_{i}\left(\theta_{i}, \theta_{i-1}, \theta_{i+1}\right) d \theta_{i+1} d \theta_{i-1} d \theta_{i} .
$$

Total entry costs are $E C=N \times F$.

Hence, social welfare with complete information is

$$
W_{k}^{*}(N) \equiv v-T C_{k}^{*}(N)-P C_{k}^{*}(N)-E C_{k}^{*}(N)
$$

while social welfare with asymmetric information is

$$
W_{k}^{e}(N) \equiv v-T C_{k}^{e}(N)-P C_{k}^{e}(N)-E C_{k}^{e}(N)
$$

where $k=T, L$ denotes the contractual structure.

Proof of Lemma 5. First, consider two-part tariffs. With complete information, using (3.3) firm $i$ 's demand is

$$
\frac{\theta_{i-1}+\theta_{i+1}-2 \theta_{i}}{4 t}+\frac{1}{N}
$$

Hence, maximizing

$$
W_{T}^{*}(N) \equiv v-\frac{8 F N^{2} t-N^{2} \sigma^{2}+2 t^{2}+8 N t \mu}{8 N t}
$$

yields the socially optimal number of firms $N_{T}^{o p t, *}=\frac{\sqrt{2} t}{\sqrt{8 F t-\sigma^{2}}}$. Recalling that $\sigma<\bar{\sigma}$, there is 
excessive entry since

$$
N_{T}^{*}>N_{T}^{o p t, *} \Leftrightarrow 36 F t>5 \sigma^{2} .
$$

With asymmetric information, using (3.11) firm $i$ 's demand is

$$
\frac{\theta_{i-1}+\theta_{i+1}-2 \theta_{i}}{2 t}+\frac{1}{N}
$$

Hence, maximizing

$$
W_{T}^{e}(N) \equiv v-\frac{12 F N^{2} t-2 N^{2} \sigma^{2}+3 t^{2}+12 N t \mu}{12 N t},
$$

yields the socially optimal number of firms $N_{T}^{o p t, e}=\frac{\sqrt{6} t}{2 \sqrt{6 F t-\sigma^{2}}}$. Recalling that $\sigma<\bar{\sigma}$, there is excessive entry since

$$
N_{T}^{e}>N_{T}^{o p t, e} \Leftrightarrow 9 F t>\sigma^{2} .
$$

Second, consider linear prices. With complete information, using (4.3) firm $i$ 's demand is

$$
\frac{\theta_{i-1}+\theta_{i+1}-2 \theta_{i}}{8 t}+\frac{1}{N}
$$

Hence, maximizing

$$
W_{L}^{*}(N) \equiv v-\frac{96 F N^{2} t-7 N^{2} \sigma^{2}+24 t^{2}+96 N t \mu}{96 N t},
$$

yields the socially optimal number of firms $N_{L}^{o p t, *}=\frac{2 t \sqrt{6}}{\sqrt{96 F t-7 \sigma^{2}}}$. Recalling that $\sigma<\bar{\sigma}$, there is excessive entry since

$$
N_{L}^{*}>N_{L}^{o p t, *} \Leftrightarrow 168 F t>13 \sigma^{2} .
$$

With asymmetric information, using (4.6) firm $i$ 's demand is

$$
\frac{\theta_{i-1}+\theta_{i+1}-2 \theta_{i}}{4 t}+\frac{1}{N}
$$

Hence, maximizing

$$
W_{L}^{e}(N) \equiv v-\frac{8 F N^{2} t-N^{2} \sigma^{2}+2 t^{2}+8 N t \mu}{8 N t},
$$

yields the socially optimal number of firms maximizes $N_{L}^{o p t, e}=\frac{\sqrt{2} t}{\sqrt{8 F t-\sigma^{2}}}$. Recalling that $\sigma<\bar{\sigma}$, there is excessive entry since

$$
N_{L}^{e}>N_{L}^{o p t, e} \Leftrightarrow 7 F t>\sigma^{2} .
$$

This concludes the proof.

Proof of Proposition 6. Recall that $\sigma<\bar{\sigma}$. First, with two-part tariffs,

$$
W_{T}^{*}\left(N_{T}^{*}\right)>W_{T}^{e}\left(N_{T}^{e}\right) \Leftrightarrow\left(3 F t-\sigma^{2}\right)\left(12 F t-\sigma^{2}\right)\left(13 \sigma^{4}+\left(900 F t-195 \sigma^{2}\right) F t\right)>0 .
$$


Moreover, in equilibrium transportation and production costs are

$$
\begin{array}{ll}
T C_{T}^{*}=\sqrt{3} \frac{\sigma^{2}+12 F t}{24 \sqrt{12 F t-\sigma^{2}}}, & T C_{T}^{e}=\sqrt{3} \frac{\sigma^{2}+3 F t}{12 \sqrt{3 F t-\sigma^{2}}}, \\
P C_{T}^{*}=\mu-\frac{\sigma^{2}}{\sqrt{3} \sqrt{12 F t-\sigma^{2}}}, & P C_{T}^{e}=\mu-\frac{\sigma^{2}}{\sqrt{3} \sqrt{3 F t-\sigma^{2}}} .
\end{array}
$$

It is straightforward to show that $P C_{T}^{*}>P C_{T}^{e}$ and that

$$
T C_{T}^{e}>T C_{T}^{*} \Leftrightarrow 108 F^{2} t^{2}+\sigma^{2}\left(15 F t-\sigma^{2}\right)>0 .
$$

Finally, $E C_{T}^{e}>E C_{T}^{*}$ since $N_{T}^{e}>N_{T}^{*}$.

Second, with linear prices,

$$
W_{L}^{e}\left(N_{L}^{e}\right)>W_{L}^{*}\left(N_{L}^{*}\right) \Leftrightarrow\left(24 F t-\sigma^{2}\right)\left(8 \sigma^{4}+1944 F^{2} t^{2}-261 F t \sigma^{2}\right)>0 .
$$

Moreover, in equilibrium transportation and production costs are

$$
\begin{array}{ll}
T C_{L}^{*}=\sqrt{3} \frac{24 F t+\sigma^{2}}{48 \sqrt{24 F t-\sigma^{2}}}, & T C_{L}^{e}=\frac{\sigma^{2}+3 F t}{12 \sqrt{2 F t}}, \\
P C_{L}^{*}=\mu-\frac{\sigma^{2}}{\sqrt{3} \sqrt{24 F t-\sigma^{2}}}, & P C_{L}^{e}=\mu-\frac{\sigma^{2}}{3 \sqrt{2 F t}} .
\end{array}
$$

It is straightforward to show that

$$
\begin{aligned}
T C_{L}^{e}>T C_{L}^{*} & \Leftrightarrow 141 F t>8 \sigma^{2}, \\
P C_{L}^{*}>P C_{L}^{e} & \Leftrightarrow 18 F t>\sigma^{2} .
\end{aligned}
$$

Finally, $E C_{L}^{*}>E C_{L}^{e}$ since $N_{L}^{*}>N_{L}^{e}$.

Proof of Proposition 7. Recall that $\sigma<\bar{\sigma}$. With complete information,

$$
\begin{aligned}
& W_{T}^{*}\left(N_{T}^{*}\right)>W_{L}^{*}\left(N_{L}^{*}\right) \\
& \quad \Leftrightarrow \quad\left(24 F t-\sigma^{2}\right)\left(12 F t-\sigma^{2}\right)\left(F^{2} t^{2}\left(214272 F t-29376 \sigma^{2}\right)+\sigma^{4}\left(1116 F t-29 \sigma^{2}\right)\right)>0 .
\end{aligned}
$$

It is straightforward to show that $T C_{T}^{*}>T C_{L}^{*}, P C_{L}^{*}>P C_{T}^{*}$, and $E C_{L}^{*}>E C_{T}^{*}$.

With asymmetric information,

$$
W_{T}^{e}\left(N_{T}^{e}\right)>W_{L}^{e}\left(N_{L}^{e}\right) \Leftrightarrow\left(3 F t-\sigma^{2}\right)\left(\sigma^{4}\left(15 F t-\sigma^{2}\right)+F^{2} t^{2}\left(93 F t-75 \sigma^{2}\right)\right)>0 .
$$

It is straightforward to show that $T C_{T}^{e}>T C_{L}^{e}, P C_{L}^{e}>P C_{T}^{e}$, and $E C_{L}^{e}>E C_{T}^{e}$. Hence, using the results of Proposition 6,

$$
W_{T}^{*}\left(N_{T}^{*}\right)>W_{T}^{e}\left(N_{T}^{e}\right)>W_{L}^{e}\left(N_{L}^{e}\right)>W_{L}^{*}\left(N_{L}^{*}\right)
$$

This concludes the proof. 


\section{References}

[1] Asker, J. (2005), "Diagnosing Foreclosure due to Exclusive Dealing." Mimeo, Stern School of Business, NYU.

[2] Bassi, M., M. Pagnozzi and S. Piccolo (2015), "Product Differentiation by Competing Vertical Hierarchies." Journal of Economics 83 Management Strategy, forthcoming.

[3] Berto Villas-Boas, S. (2007), "Vertical Relationships between Manufacturers and Retailers: Inference with Limited Data." Review of Economic Studies, 74, 625-652.

[4] Blair, F., and T. Lewis (1994), "Optimal Retail Contracts with Asymmetric Information and Moral Hazard." RAND Journal of Economics, 25, 284-296.

[5] Bonanno, G., and J. Vickers (1988), "Vertical Separation." Journal of Industrial Economics, 36, 257-265.

[6] Bonnet, C., and P. Dubois (2010), "Inference on Vertical Contracts Between Manufacturers and Retailers Allowing for Nonlinear Pricing and Resale Price Maintenance." RAND Journal of Economics, 41, 139-164.

[7] Cachon, G. P. and P. T. Harker (2002), "Competition and Outsourcing with Scale Economies." Management Science, 48, 1314-1333.

[8] Caillaud, B., B. Jullien and P. Picard (1995), "Competing Vertical Structures: Precommitment and Renegotiation." Econometrica, 63, 621-646.

[9] Christopher, M. and D. R. Towell (2000), "Supply Chain Migration from Lean and Functional to Agile and Customized." Supply Chain Management, 5, 206-213.

[10] Coughlan, A. T. (1985), "Competition and Cooperation in Marketing Channel Choice: Theory and Application." Marketing Science, 4, 110-129.

[11] Coughlan, A. T. and B. Wernerfelt (1989), "On Credible Delegation by Oligopolists: A Discussion of Distribution Channel Management." Management Science, 35, 226-239.

[12] Fudenberg, D., and J. Tirole (1991), Game Theory. Cambrigde, MA: MiT Press..

[13] Gal-Or, E. (1991), "Vertical Restraints with Incomplete Information." Journal of Industrial Economics, 39, 503-516.

[14] GaL-Or, E. (1999), "Vertical Integration or Separation of the Sales Functions as Implied by Competitive Forces." International Journal of Industrial Organization, 17, 641-662.

[15] Ghosh, A. and H. Morita (2007), "Free Entry and Social Efficiency under Vertical Oligopoly." RAND Journal of Economics, 38 (2), 541-554.

[16] Inderst, R., and T. Valletti (2009), "Price Discrimination in Input Markets." RAND Journal of Economics, 40, 1-19.

[17] Iyer, G., and J.M. Villas-Boas (2003), "A Bargaining Theory of Distribution Channels." Journal of Marketing Research, 40, 80-100.

[18] Jullien, B., and P. Rey (2007), "Resale Price Maintenance and Collusion." RAND Journal of Economics, 38, 983-1001.

[19] Kastl, J., D. Martimort and S. Piccolo (2011), "When Should Manufacturers Want Fair Trade? New Insights from Asymmetric Information." Journal of Economics 83 Management Strategy, 3, 649-677. 
[20] KATz, M. (1986), "An Analysis of Cooperative Research and Development." RAND Journal of Economics, 17, 527-543.

[21] Katz, M. (1991), "Game-Playing Agents: Unobservable Contracts as Precommitments." RAND Journal of Economics, 22, 307-328.

[22] Laffont, J.J., and D. Martimort (2000), The Theory of Incentives: The PrincipalAgent Model. Princeton, NJ: Princeton University Press.

[23] Lafontaine, F., and M. Slade (1997), "Retailing Contracting: Theory and Practice." Journal of Industrial Economics, 45, 1-25.

[24] Lafontaine, F., and K.L. Shaw (1999), "The Dynamics of Franchise Contracting: Evidence from Panel Data." Journal of Political Economy, 107, 1041-1080.

[25] Martimort, D. (1996), "Exclusive Dealing, Common Agency, and Multiprincipals Incentive Theory." RAND Journal of Economics, 27, 1-31.

[26] Martimort, D., and S. Piccolo (2010), "The Strategic Value of Quantity Forcing Contracts." American Economic Journal: Microeconomics, 2, 204-229.

[27] Martimort, D., and A. Semenov (2006), "Continuity in Mechanism Design without Transfers." Economics Letters, 93, 182-189.

[28] Maskin, E., and J. Tirole (1990), "The Principal-Agent Relationship with an Informed Principal: The Case of Private Values." Econometrica, 58, 379-409.

[29] Myerson, R. (1982), "Optimal Coordination Mechanisms in Generalized Principal-Agent Problems." Journal of Mathematical Economics, 11, 67-81.

[30] McGuire, T., and R. Staelin (1983), "An Industry Equilibrium Analysis of Downstream Vertical Integration." Marketing Science, 2, 161-191.

[31] Mortimer, J. (2008), VVertical Contracts in the Video Rental Industry." Review of Economic Studies, 75, 165-199.

[32] Motta, M. (2004) Competition Policy: Theory and Practice. Cambirdge University Press.

[33] O'Brien, D., and G. Shaffer (1992), "Vertical Control with Bilateral Contracts." RAND Journal of Economics, 23(3), 299-308.

[34] Pagnozzi, M., and S. Piccolo (2012), "Vertical Separation with Private Contracts." Economic Journal, 122, 173-207.

[35] Raith, M. (2003), "Competition, Risk and Managerial Incentives." American Economic Review, 93, 1425-1436.

[36] Reisinger, M., and M. Schnitzer (2012), "Successive Oligopolies with Differentiated Firms and Endogenous Entry." Journal of Industrial Economics, 60, 537-577.

[37] Rey, P., and J. Stiglitz (1995), "The Role of Exclusive Territories in Producers' Competition." RAND Journal of Economics, 26, 431-451.

[38] Salop, S.C. (1979), "Monopolistic Competition with Outside Goods." Bell Journal of Economics, 10, 141-156.

[39] Vickers, J. (1985), "Delegation and the Theory of the Firm." Economic Journal, 95, $138-47$. 
[40] Vogel, J. (2008), "Spatial Competition with Heterogeneous Firms." Journal of Political Economy, 116 (3), 423-466. 